\title{
低成本、高性能钻钛矿电池有机小分子空穴传输材料
}

\author{
邵将洋 $a$ 钟羽武 $*, a, b$ \\ $\left({ }^{a}\right.$ 中国科学院化学研究所光化学重点实验室 北京 100190) \\ ( $b$ 中国科学院大学化学学院 北京 100049)
}

\begin{abstract}
摘要 钙铁矿太阳能电池由于其高能量转换效率(最高报道认证效率为 $25.2 \%$ )、低成本和易于制造等特点, 成为下一代 光伏技术的关注焦点. 虽然䥻铁矿材料本身可以传导空穴, 但其效率比较低. 空穴传输材料的使用成为有效提取电荷 和提高钲针矿型太阳能电池效率的关键因素. 总结了近期报道的低成本、高性能有机小分子空穴传输材料(效率大于 $19 \%)$, 从螺环结构、噻吩衍生物以及其它结构进行介绍, 并从合成策略和化学修饰等角度评估结构一性能的构效关系及 其对器件效率和稳定性的影响，最后对有机小分子空穴传输材料的发展趋势进行了展望.
\end{abstract}

关键词＼cjkstart钻钣矿太阳能电池; 空穴传输材料; 有机功能分子; 三芳胺; 能量转换效率

\section{Low-Cost, High-Performance Organic Small Molecular Hole-Transporting Materials for Perovskite Solar Cells}

\author{
Shao, Jiang-Yang ${ }^{a} \quad$ Zhong, Yu-Wu*,a,b \\ $\left({ }^{a}\right.$ Key Laboratory of Photochemistry, Institute of Chemistry, Chinese Academy of Sciences, Beijing 100190) \\ ( ${ }^{b}$ School of Chemical Sciences, University of Chinese Academy of Sciences, Beijing 100049)
}

\begin{abstract}
Perovskite solar cells (PSCs) have become the focus of interest among next-generation photovoltaic technologies attributed to their outstanding power conversion efficiency (PCE) (the highest certified PCE of $25.2 \%$ being achieved to date), low cost and fabrication feasibility. Perovskite itself is hole-conductive, albeit with a low efficiency. The use of hole transporting material (HTM) remains indispensable for the efficient charge extraction in high-performance PSCs. The recent design and development of low-cost organic small molecules as HTMs in high-performance PSCs with a PCE over 19\% are summarized. These HTMs are categorized into materials with spiro core structures, thiophene derivatives, and others, on the basis of their structural features. The relationship between molecular structure and device performance is discussed from the perspective of synthetic strategy and chemical modification. Finally, an outlook is given on the future development of small molecular HTMs. Keywords perovskite solar cell; hole transporting material; organic functional molecule; triarylamine; power conversion efficiency
\end{abstract}

近年来，钻钛矿(Perovskite)材料因其具有高消光系 数、合适可调的带隙、长电荷扩散范围、优良的双极性 载流子输运性质、较宽的光谱吸收范围、简单的制备工 艺以及温和的制备条件等优点, 在太阳能电池和其它光 电领域中受到广泛关注 ${ }^{[1]}$. 太阳能电池钲钛矿材料通常 指有机一无机杂化钙铁矿金属卤化物 $\mathrm{ABX}_{3}$ 材料 ${ }^{[2]}, \mathrm{A}$ 为 一价阳离子如 $\mathrm{CH}_{3} \mathrm{NH}_{3}^{+}$(甲胺, $\mathrm{MA}^{+}$)、 $\mathrm{CH}_{2}\left(\mathrm{NH}_{2}\right)_{2}^{+}$(甲 咪, $\mathrm{FA}^{+}$)和 $\mathrm{Cs}^{+}$等, $\mathrm{B}$ 为过渡金属二价离子, 如 $\mathrm{Pb}^{2+}$ 和 $\mathrm{Sn}^{2+}$ 等, $\mathrm{X}$ 为卤素阴离子 $\left(\mathrm{Cl}^{-} 、 \mathrm{Br}^{-} 、 \mathrm{I}^{-}\right)$. 其中, 位于体心
的 $\mathrm{B}$ 阳离子与处在 6 个面心上的 $\mathrm{X}$ 阴离子形成一个 $\mathrm{BX}_{6}$ 正八面体结构, $\mathrm{BX}_{6}$ 八面体通过交点 $\mathrm{X}$ 向三围方向延伸. $\mathrm{A}$ 阳离子填充在由 8 个 $\mathrm{BX}_{6}$ 八面体组成的立方八面体的 空隙中来维持电荷平衡. 通过调节 $\mathrm{A} 、 \mathrm{~B} 、 \mathrm{X}$ 离子的大 小, 可以得到不同晶体结构的钻钛矿型材料. 2009 年, Miyasaka 小组 ${ }^{[3]}$ 将甲胺铅碘 $\left(\mathrm{MAPbI}_{3}\right)$ 作为吸光材料引入 到染料敏化太阳能电池中, 取得了 $3.8 \%$ 的能量转换效 率(power conversion efficiency, PCE). 该工作中使用的 液态电解质容易破坏钙钛矿吸光材料, 其器件的稳定性

\footnotetext{
* Corresponding author. E-mail: zhongyuwu@iccas.ac.cn

Received September 14, 2020; published November 2, 2020; published online November 11, 2020.

Project supported by the Beijing Municipal Natural Science Foundation (No. 2191003) and the National Natural Science Foundation of China (Nos. 21975264 21872154, 21922512).

北京市自然科学基金(No. 2191003)和国家自然科学基金(Nos. 21975264, 21872154, 21922512)资助项目.
} 
很差, 而且液态电解质的使用也不利于后期的器件封 装. 为了解决这些问题, Kim 等 ${ }^{[4]}$ 使用 $2,2^{\prime}, 7,7^{\prime}$-四 $[N, N$ 二(4- 甲氧基苯基)氨基]-9, $9^{\prime}$ - 螺二芴 (2,2',7,7'-tetrakis( $N, N$ - $p$-dimethoxy-phenylamino)-9,9'-spirobifluorene, spiro-OMeTAD) 代替液态电解质, 在相应的固态电池中取 得 9.7\%效率, 并大大提高了器件的稳定性. 目前, 钙钛 矿太阳能电池的最高报道认证效率已经达到 $25.2 \%{ }^{[5]}$, 可以与多晶硅薄膜电池相媲美. 虽然钻钣矿材料本身可 以传导空穴, 但其效率比较低. 在高性能的钙钛矿太阳 能电池中, 空穴传输材料(Hole transport material, HTM) 的使用起到了从钙钛矿吸光层提取和传输空穴的关键 作用. 在这篇综述中, 总结了近期在钙钛矿太阳能电池 中取得高能量转换效率(PCE $>19 \%)$ 的有机小分子空穴 传输材料, 根据分子的结构特点, 从螺环结构、噻吩衍 生物以及其它结构三类化合物进行介绍, 并分析它们的 分子设计和合成路线, 探讨其分子结构对器件性能的影 响.

\section{1 钙钛矿太阳能电池}

钙钛矿型太阳能电池主要由透明导电玻璃基底 (ITO/FT0)、电子传输层(Electron transport layer, ETL)、 钙钛矿层、空穴传输层(Hole transport layer, HTL)以及金 属电极 $(\mathrm{Au} 、 \mathrm{Ag} 、 \mathrm{Al}$ 等) 几部分组成. 目前, 常见的钙钛 矿电池结构有三种, 分别是介孔 n-i-p 型结构、平面 n-i-p 型结构和平面 p-i-n 型结构(图 1) ${ }^{[6]}$. 介孔 n-i-p 型结构是 钙铁矿太阳能电池发展初期的一种主要器件结构, 它的 组成为氟掺杂氧化锡( $\mathrm{FTO})$ 基底/致密 $\mathrm{TiO}_{2}\left(\mathrm{c}-\mathrm{TiO}_{2}\right) /$ 介孔 $\mathrm{TiO}_{2}\left(\mathrm{mp}-\mathrm{TiO}_{2}\right) /$ 钙钛矿层/空穴传输层/金属电极. 该结 构的不足之处在于其电荷复合几率相对较高, 且制备过 程需要高温处理, 不利于柔性器件的制造. 相比较, 平 面 n-i-p 型结构的器件制备工艺相对简单, 避免了介孔 层所需要的高温处理工序. 平面 p-i-n 结构(也称反式结 构)的组成主要包括基底/空穴传输层/钻钣矿层/电子传 输层/金属电极. 它的特点是钙铁矿薄膜沉积在空穴传 输层上. 如图 2 所示, 钙铁矿太阳能电池的工作过程主 要包括三个步骤: 钙铁矿层激子的产生、激子的分离和 扩散以及载流子的传输与收 集 ${ }^{[7]}$. 主要工作原理是太 阳光照射到电池后, 钙钛矿活性层受到光激发产生电子 -空穴对，电子跃迁到钙钛矿的导带中，而空穴留在钙 铁矿层的价带中. 随后生成的电子和空穴分别通过电子 传输层和空穴传输层向两边传输到外电路, 形成完整的 闭合回路产生光电流.

\section{2 空穴传输材料}

空穴传输材料作为钙钛矿太阳能电池的重要组成

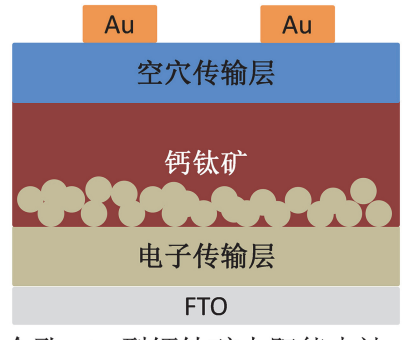

介孔n-i-p型钙钛矿太阳能电池

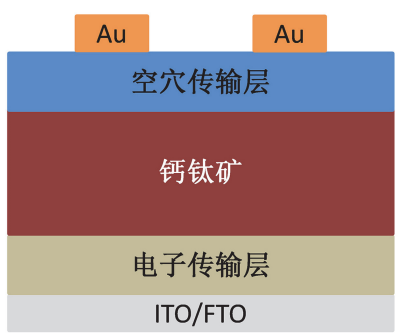

平面n-i-p型钙钛矿太阳能电池

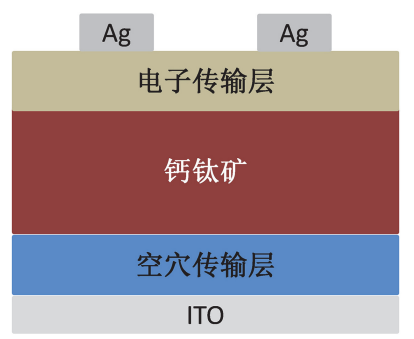

平面p-i-n型钙钛矿太阳能电池

图 1 钻钛矿太阳电池结构示意图

Figure 1 Structures of perovskite solar cells

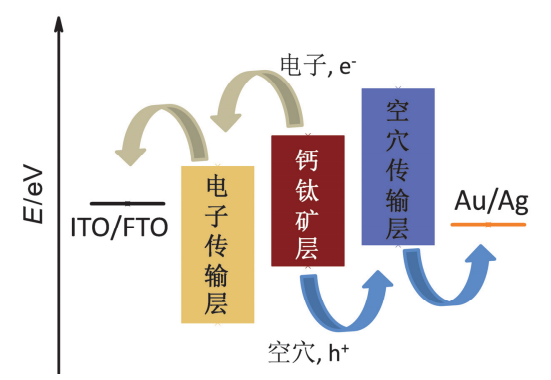

图 2 PSCs 器件中电荷传输示意图

Figure 2 Schematic representation of charge transfer processes in PSCs

部分，它的主要作用是收集并传输由钲钛矿吸收层注入 的空穴, 实现电子-空穴有效分离 ${ }^{[8]}$. 空穴传输材料的使 用还可以改善钻钛矿层与金属电极间的肖特基接触，并 形成良好的欧姆接触，提高器件的效率. 理想的空穴传 输材料应满足以下要求: (1)具有良好的疏水性和热、光、 化学稳定性; (2)最高占据分子轨道(HOMO) 能级稍高于 钙铁矿材料价带(最好不超过 $0.3 \mathrm{eV}$ ), 保证空穴的有效 提取与注入, 同时较深的 $\mathrm{HOMO}$ 能级导致较高的开路 电压; (3)较高的空穴迁移率 $\left(\approx 10^{-4} \mathrm{~cm}^{2} \cdot \mathrm{V}^{-1} \cdot \mathrm{s}^{-1}\right)$ 保证空 穴可以快速传输到电极; (4)较好的溶解度, 以获得更好 
的成膜性能; (5)玻璃化转变温度 $\left(T_{\mathrm{g}}\right)>120{ }^{\circ} \mathrm{C}$, 防止在 器件工作时发生相变; (6)低廉的制备和生产成本.

除了上述要求之外, 根据器件结构的不同, 空穴传 输材料的设计还应注意以下几点. 在正式器件结构中, 空穴传输材料和钙钛矿表面需要有较好的正交溶解性, 以防在沉积空穴传输层时破坏钻钛矿. 同时需要两者之 间有较好的界面接触, 有利于提取和传输空穴. 除此之 外, 空穴传输层还可以隔绝空气中的水和氧气, 保护钙 钛矿层, 提高器件的稳定性. 因此, 良好的疏水性和稳 定性是正式器件结构空穴传输材料设计时需要着重考 虑的因素. 在反式器件结构中, 直接在透明导电玻璃基 底上沉积空穴传输层. 在空穴传输材料的设计时, 应考 虑 HTM 的成膜方式及其与基底的界面相互作用. 空穴 传输材料应该与钙钛矿之间有良好的接触且不发生反 应, 这可以促进钙铁矿结晶并形成高质量的钙铁矿薄 膜. 此外, 在反式结构中, 太阳光在被钙钛矿材料吸收 之前需要透过空穴传输层. 为了高效利用太阳光, 空穴 传输材料需要具有高透光性, 减少与钻钣矿层的光吸收 竞争.

空穴传输材料主要包括有机和无机两类. 无机空穴 传输材料具有成本低和导电率高等优点, 并且可用通过 不同离子掺杂进行改性. 无机空穴传输材料可能的一些 缺点是制备过程需要高温以及重现性会受到杂质及制 备工艺较大的影响. 无机空穴传输材料主要有 $\mathrm{NiO}_{x}$ 、 $\mathrm{CuSCN}$ 和 $\mathrm{CuO}$ 等 ${ }^{[9]}$. 有机空穴传输材料主要包括小分 子和聚合物材料, 可以通过分子设计与化学修饰达到结 构灵活以及能级可控调节的目的. 标准的有机小分子空 穴传输材料主要是 Spiro-OMeTAD(图 3, 1). 根据分子结 构特点, 常用的有机小分子空穴传输材料包括含螺环结 构有机分子空穴传输材料、含噻吩结构有机小分子空穴 传输材料以及其他有机小分子空穴传输材料等类型. 经 典聚合物空穴传输材料主要有 $(3,4$-亚乙二氧基噻吩) -聚 (苯乙烯磺酸)(PEDOT:PSS)和聚[双(4-苯基)(2,4,6-三甲 基苯基)胺](PTAA)等 ${ }^{[10]}$.

\section{3 有机小分子空穴传输材料}

\section{1 含螺环结构的有机小分子空穴传输材料}

目前, 钻钛矿太阳能电池中应用最广泛且性能优异 的有机小分子空穴传输材料是含螺环结构的 SpiroOMeTAD 分子. 2012 年, Kim 等 ${ }^{[4]}$ 报道了以 spiroOMeTAD 为空穴传输材料的 $\mathrm{MAPbI}_{3}$ 太阳能电池, 该固 态电池的 PCE 达到当时最高的 9.7\%. spiro-OMeTAD 具 有与 $\mathrm{MAPbI}_{3}$ 价带匹配的 $\mathrm{HOMO}$ 能级和较大的带隙宽 度, 有利于取得较高电池效率. 螺环分子中螺环结构的 引入提高了分子玻璃转化温度, 改善了分子使用过程中
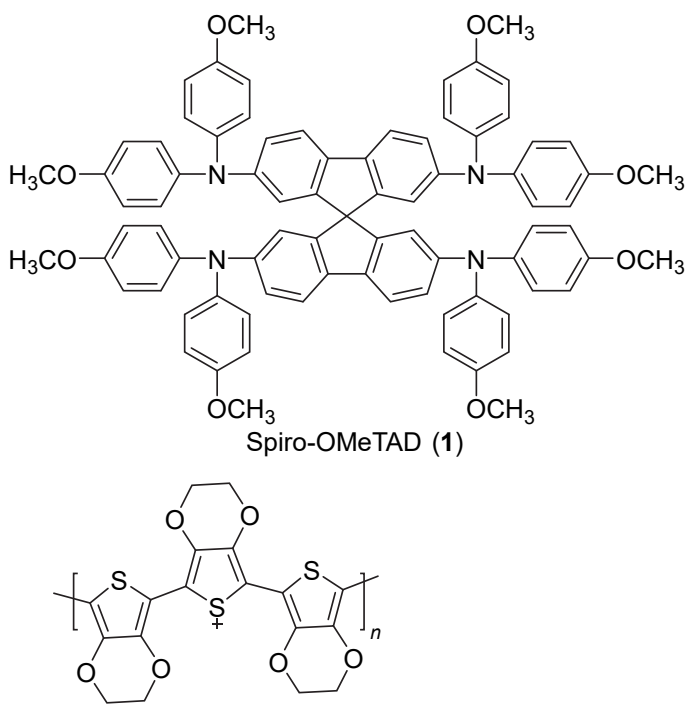

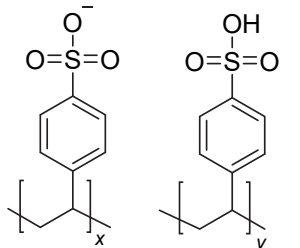

PEDOT:PSS

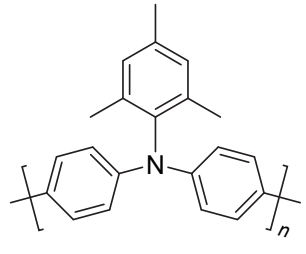

PTAA
图 3 Spiro-OMeTAD、PEDOT:PSS 和 PTAA 结构式 Figure 3 Structures of Spiro-OMeTAD、PEDOT:PSS and PTAA

的结晶性质. 而且, 非平面的三维螺环结构使得 spiroOMeTAD 分子在有机溶剂中有良好的溶解性, 有利于 在钙铁矿表面形成高质量均匀的空穴传输材料薄膜. 最 近, Seok 等 ${ }^{[1]}$ 通过对以 spiro-OMeTAD 为空穴传输材料 的太阳电池的钙钛矿层进行优化, 其 PCE 最高已经达 到 $23.7 \%$, 这是目前公开发表的基于 spiro-OMeTAD 空 穴传输材料的最高钙钛矿太阳电池效率. 由于 spiroOMeTAD 中心螺环结构螺二芴的合成工艺较为复杂, 需经过 5 步条件苛刻的反应才制备得到(Scheme 1), 成 本较高，限制了其在钙钛矿领域的进一步商业化应 用 ${ }^{[12]}$. 同时, Spiro-OMeTAD 的非平面螺环结构导致分 子间隔距离拉长, 致使该材料的空穴迁移率较低. 为了 获得更高效率的器件, 通常需要掺杂 4-叔丁基吡啶 (4-tert-butyl-pyridine, TBP)和二(三氟甲基磺酸酰)亚胺 锂(lithium bis(trifluoromethanesulfonyl)imide, LiTFSI)等 添加剂. 由于 LiTFSI 等添加剂的吸湿性质, 导致钻钛矿 加速降解, 限制了器件的长期稳定性, 而且还会增加器 件制备的复杂性和成本. 因此, 设计、合成其它廉价高 效的空穴传输材料来代替 spiro-OMeTAD 引起众多研究 小组的兴趣.

鉴于此, 研究人员围绕 spiro-OMeTAD 类似的螺环 结构进行了一系列的分子设计和结构修饰来提高钻钛 矿太阳能电池的能量转换效率和稳定性, 并降低材料的 
合成成本. 表 1 列举了它们的能级、空穴迁移率及制备 成电池的性能参数. Seo 等 ${ }^{[13]}$ 将芴单元作为 spiroOMeTAD 的新外围基团, 合成了芴封端的新螺环分子 $\mathrm{DM}$ (2). 将甲氧基苯基用芴基取代可以减弱分子的供电 子能力, 导致 2 有较高的氧化电位和较深的 HOMO 能 级. 这种封端取代降低了钙钛矿层与空穴传输层之间界 面处的费米能级, 并最终增加器件的开路电压 $\left(V_{\mathrm{oc}}\right)$. 另 外, 和 spiro-OMeTAD 的 $T_{\mathrm{g}}\left(121{ }^{\circ} \mathrm{C}\right)$ 相比, 刚性芴单元 的引入将 2 的 $T_{\mathrm{g}}$ 提高至 $161{ }^{\circ} \mathrm{C}$, 增强了其热稳定性. 基 于 2 的器件表现出较高的效率(0.09 和 $1 \mathrm{~cm}^{2}$ 有效面积器 件的效率分别为 $23.2 \%$ 和 $21.7 \%$ ) 和良好的热稳定性. 在 $60{ }^{\circ} \mathrm{C}$ 退火后, 封装的器件在超过 $500 \mathrm{~h}$ 的时间内保持其 初始效率的 $95 \%$.

Nazeeruddin 及其同事 ${ }^{[14]}$ 在 2016 年开发了空穴传输 材料 $2^{\prime}, 7^{\prime}$-双(4-甲氧基苯基)胺基螺环戊二噻吩芴(FDT) (3). 该化合物通过钯催化双(4-甲氧基苯基)胺与二溴螺 环化合物的交叉偶联，以超过 $80 \%$ 的产率制备. 经估算， FDT 的合成成本 $\left(60 \$ \cdot \mathrm{g}^{-1}\right)$ 大大低于 spiro-OMeTAD $\left(100 \sim 300 \$ \cdot \mathrm{g}^{-1}\right)$. 除了甲氧基与钻钛矿中甲胺位点之 间的相互作用外，额外的噻吩/碘相互作用和分子间 S/S

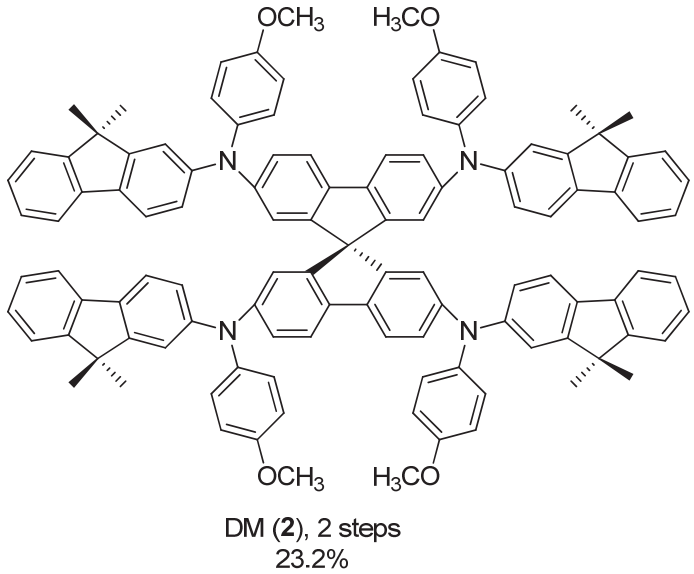

接触可以改善 FDT/钲钛矿界面上的空穴传输. FDT 的 HOMO 能级为 $-5.16 \mathrm{eV}$, 和 spiro-OMeTAD 的 HOMO 能级相当. 基于混合 $\left(\mathrm{FAPbI}_{3}\right)_{0.85}\left(\mathrm{MAPbBr}_{3}\right)_{0.15}$ 钻钛矿器 件, 使用 LiTFSI, TBP 和 FK209 作为添加剂, FDT 作为 空穴传输材料, 取得最大能量转化效率为 $20.2 \%, V_{\mathrm{oc}}$ 为 $1.15 \mathrm{~V}$, 短路电流 $\left(J_{\mathrm{sc}}\right)$ 为 $22.7 \mathrm{~mA} \cdot \mathrm{cm}^{-2}$, 填充因子 $(F F)$ 为 0.76. 在相同条件下略胜于基于 spiro-OMeTAD 的参比 器件 $(\mathrm{PCE}=19.7 \%)$. 此外, 基于 FDT 的器件在干燥条件

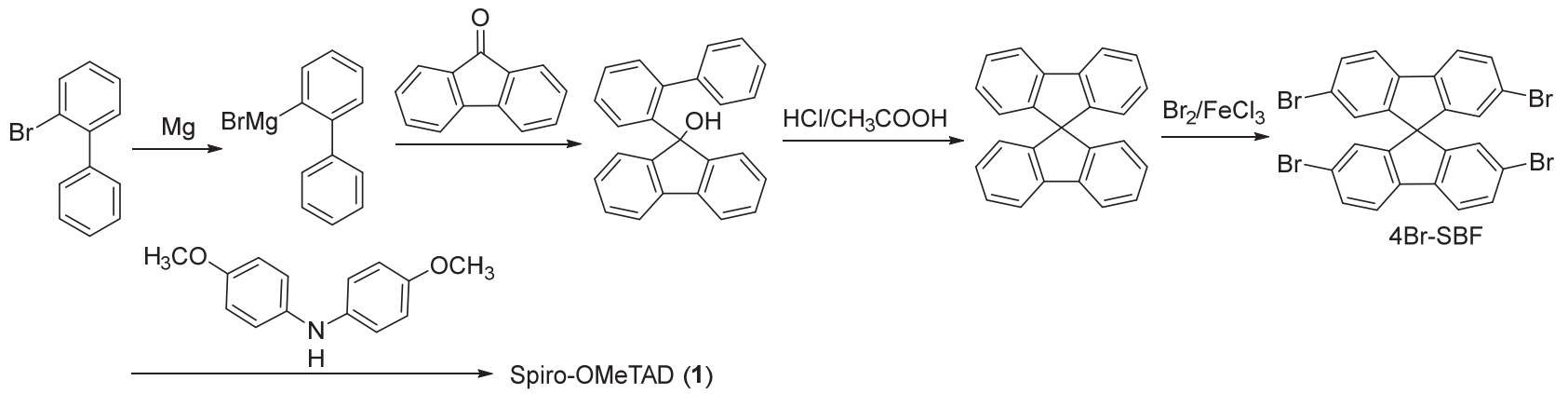

图式 1 Spiro-OMeTAD 的合成路线

Scheme 1 Synthetic route of spiro-OMeTADs

表 1 不同空穴传输材料的能级及制备成电池的性能参数

Table 1 Energy levels of different HTMs and the performance parameters of the devices

\begin{tabular}{|c|c|c|c|c|c|}
\hline Device configuration & $\begin{array}{c}\mathrm{HOMO} \\
\mathrm{eV}\end{array}$ & $\begin{array}{l}\text { / Hole mobility/ } \\
\left(\mathrm{cm}^{2} \cdot \mathrm{V}^{-1} \cdot \mathrm{s}^{-1}\right)\end{array}$ & $V_{\mathrm{oc}} / \mathrm{V}$ & $\begin{array}{c}J_{\mathrm{sc} /} \\
\left(\mathrm{mA} \cdot \mathrm{cm}^{-2}\right)\end{array}$ & FF PCE/\%Ref. \\
\hline 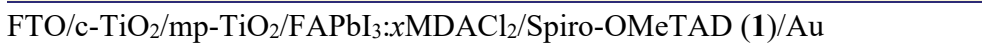 & -5.22 & $5.31 \times 10^{-5}$ & 1.15 & 26.1 & $0.7923 .7[11]$ \\
\hline ]FTO/c- $\mathrm{TiO}_{2} / \mathrm{mp}-\mathrm{TiO}_{2} / \mathrm{FA}_{1-x} \mathrm{MA}_{x} \mathrm{~Pb}\left(\mathrm{I}_{1-y} \mathrm{Br}_{y}\right)_{3} / \mathrm{DM}(\mathbf{2}) / \mathrm{Au}$ & -5.27 & $\mathrm{NR}^{a}$ & 1.11 & 24.8 & $0.8123 .2[13]$ \\
\hline $\mathrm{FTO} / \mathrm{c}-\mathrm{TiO}_{2} / \mathrm{mp}-\mathrm{TiO}_{2} / \mathrm{FA}_{1-x} \mathrm{MA}_{x} \mathrm{~Pb}\left(\mathrm{I}_{1-y} \mathrm{Br}_{y}\right)_{3} / \mathrm{FDT}(\mathbf{3}) / \mathrm{Au}$ & -5.16 & $\mathrm{NR}^{a}$ & 1.15 & 22.7 & $0.7620 .2[14]$ \\
\hline ITO/DFH(4)/MA ${ }_{0.9} \mathrm{FA}_{0.1} \mathrm{PbI}_{3-x} \mathrm{Cl}_{x} / \mathrm{C}_{60} / \mathrm{BCP} / \mathrm{Ag}$ & -5.27 & $1 \times 10^{-3}$ & 1.10 & 22.6 & $0.8320 .6^{b}[15]$ \\
\hline $\mathrm{FTO} / \mathrm{c}-\mathrm{TiO}_{2} / \mathrm{mp}-\mathrm{TiO}_{2} / \mathrm{FA}_{1-x} \mathrm{MA}_{x} \mathrm{~Pb}\left(\mathrm{I}_{1-y} \mathrm{Br}_{\mathrm{y}}\right)_{3} / \mathrm{X} 60(\mathbf{5}) / \mathrm{Au}$ & $\mathrm{NR}^{a}$ & $1.9 \times 10^{-4}$ & 1.14 & 24.2 & $0.7119 .84[16]$ \\
\hline $\mathrm{FTO} / \mathrm{c}-\mathrm{TiO}_{2} / \mathrm{mp}-\mathrm{TiO}_{2} / \mathrm{FA}_{1-x} \mathrm{MA}_{x} \mathrm{~Pb}\left(\mathrm{I}_{1-y} \mathrm{Br}_{\mathrm{y}}\right)_{3} / \mathrm{X} 59(\mathbf{6}) / \mathrm{Au}$ & -5.13 & $5.5 \times 10^{-5}$ & 1.13 & 23.4 & $0.7319 .8[17]$ \\
\hline $\mathrm{FTO} / \mathrm{c}-\mathrm{TiO}_{2} / \mathrm{mp}-\mathrm{TiO}_{2} /\left[\mathrm{HC}\left(\mathrm{NH}_{2}\right)_{2}\right]_{0.85}\left(\mathrm{CH}_{3} \mathrm{NH}_{3}\right)_{0.15} \mathrm{~Pb}\left(\mathrm{I}_{0.85} \mathrm{Br}_{0.15}\right)_{3} / \mathrm{X} 55(7) / \mathrm{Au}$ & -5.23 & $6.81 \times 10^{-4}$ & 1.15 & 23.4 & $0.7720 .8[18]$ \\
\hline $\mathrm{FTO} / \mathrm{c}-\mathrm{TiO}_{2} / \mathrm{mp}-\mathrm{TiO}_{2} /\left[\mathrm{HC}\left(\mathrm{NH}_{2}\right)_{2}\right]_{0.85}\left(\mathrm{CH}_{3} \mathrm{NH}_{3}\right)_{0.15} \mathrm{~Pb}\left(\mathrm{I}_{0.85} \mathrm{Br}_{0.15}\right)_{3} / \mathrm{X} 26(\mathbf{8}) / \mathrm{Au}$ & -5.08 & $2.79 \times 10^{-4}$ & 1.11 & 24.3 & $0.7520 .2[19]$ \\
\hline $\mathrm{FTO} / \mathrm{c}-\mathrm{TiO}_{2} / \mathrm{mp}-\mathrm{TiO}_{2} /\left(\mathrm{FAPbI}_{3}\right)_{0.095}\left(\mathrm{MAPbBr}_{3}\right)_{0.05} / \mathrm{SFXDAnCBZ}(\mathbf{9}) / \mathrm{Au}$ & -4.95 & $4.28 \times 10^{-4}$ & 1.09 & 23.1 & $0.8320 .87[20]$ \\
\hline $\mathrm{FTO} / \mathrm{c}-\mathrm{TiO}_{2} / \mathrm{mp}-\mathrm{TiO}_{2} /\left[\mathrm{HC}\left(\mathrm{NH}_{2}\right)_{2}\right]_{0.85}\left(\mathrm{CH}_{3} \mathrm{NH}_{3}\right)_{0.15} \mathrm{~Pb}\left(\mathrm{I}_{0.85} \mathrm{Br}_{0.15}\right)_{3} / \mathrm{G} 2(\mathbf{1 0}) / \mathrm{Au}$ & -5.22 & $3.58 \times 10^{-4}$ & 1.13 & 23.5 & $0.7620 .2[21]$ \\
\hline $\mathrm{FTO} / \mathrm{c}-\mathrm{TiO}_{2} / \mathrm{mp}-\mathrm{TiO}_{2} / \mathrm{CsMAFA}_{\mathrm{HTM}}-1$ (11)/Au & -5.01 & $4.5 \times 10^{-4}$ & 1.10 & 24.7 & $0.7721 .0[22]$ \\
\hline $\mathrm{FTO} / \mathrm{TiO}_{2} / \mathrm{MAPbI}_{3} / \mathrm{SCZF}-5$ (12)/ $\mathrm{MoO}_{3} / \mathrm{Ag}$ & -5.17 & $4.69 \times 10^{-4}$ & 1.11 & 24.4 & $0.7420 .1 \quad[24]$ \\
\hline $\mathrm{FTO} / \mathrm{SnO}_{2} / \mathrm{CsFAMA} /$ spiro-CN-OMeTAD (13)/Au & -5.16 & $1.04 \times 10^{-4}$ & 1.16 & 22.0 & $0.78 \quad 19.9[26]$ \\
\hline
\end{tabular}

${ }^{a} \mathrm{NR}=$ not reported. ${ }^{b}$ Dopant-free. 
<smiles></smiles>

下存放 $60 \mathrm{~d}$ 后效率几乎没有下降, 表现出很好的器件稳 定性.

2019 年, Berlinguette 课题组 ${ }^{[15]}$ 合成了 $N^{2}, N^{2}, N^{7}, N^{7}$ 四对甲苯二氧戊环缩酮芴二胺(DFH) (4). DFH 通过 2,7二溴-9-芴酮的 Buchwald-Hartwig 胺化反应以及酸性条 件下与乙二醇的缩合反应以 $73 \%$ 的总反应产率合成得 到(Scheme 2). 该合成方法中, 每步反应的产物可以通 过重结晶纯化. 它的实验室成本大约为 $3 \$ \bullet \mathrm{g}^{-1}$, 这是其 他任何有机 HTM 都无法比拟的, 而且容易实现按比例 缩放, 也不会出现无机和聚合物空穴传输材料的批次差 异问题. DFH 表现出低的氧化还原重组能以及高的玻璃 化转变温度 $\left(T_{\mathrm{g}}=135{ }^{\circ} \mathrm{C}\right)$. 强的分子间相互作用使 $\mathrm{DFH}$ 分子具有较高的空穴迁移率 $\left(1 \times 10^{-3} \mathrm{~cm}^{2} \cdot \mathrm{V}^{-1} \cdot \mathrm{s}^{-1}\right)$. 此 外, 芴桥可以介导两个氧化还原活性中心之间的强电子 偶合, 这种强大的电子偶合会将 HOMO 能级提高至一 $5.27 \mathrm{eV}$. HOMO 能级的提高既能保持器件较高的开路电 压, 又仍能从钻钣矿 $(-5.4 \mathrm{eV})$ 中提取空穴, 实现有效 的电荷分离. 退火后的 DFH 膜有助于形成大晶粒钙钛 矿 $($ 最大 $2 \mu \mathrm{m}$ ), 从而减小电荷重组. 在没有任何掺杂剂 或修饰层的情况下, 基于 DFH 的反向器件获得最高 $20.6 \%$ 的能量转换效率.

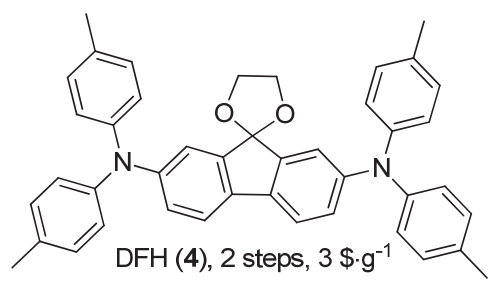

$20.6 \%$

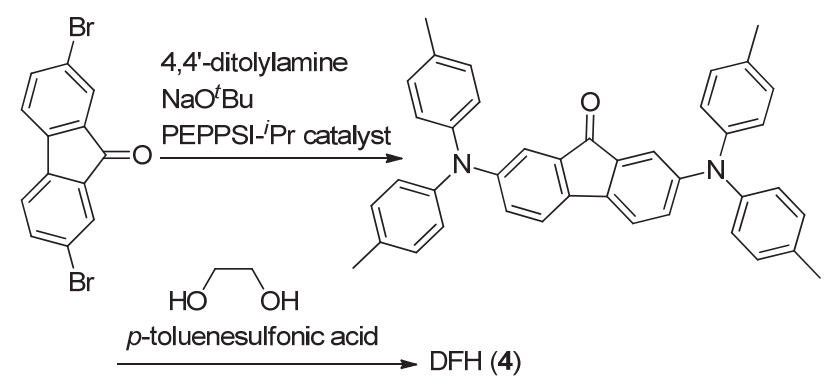

图式 $2 \mathrm{DFH}$ 的合成路线

Scheme 2 Synthetic route of DFH

制备 spiro-OMeTAD 所需的四溴螺二荡(4Br-SBF)
需要复杂的合成路线和较高的合成成本. 鉴于此, 孙立 成和 Hagfeldt 等 ${ }^{[16]}$ 利用廉价的苯酚和 9-荡酮为起始原 料, 通过一锅反应合成四溴螺 [ 芴 $-9,9^{\prime}$-氧杂葱] (4BrSFX), 其产率高达 90\%以上(Scheme 3). 更重要的是, 螺[芴-9,9'-氧杂葱](SFX)的合成成本约为螺二芴 (SBF) 的 $1 / 30$, 使得基于 SFX 骨架的分子非常适合大规模工业生 产. 此外, 基于 SFX 构建的垂直螺环结构可以有效抑制 分子间 $\pi-\pi$ 堆积, 从而提高它的溶解度. 他们合成了一 种低成本的空穴传输材料 X60 (5), 四个端基用双甲氧 基苯胺进行封端. X60 的合成路线很简单，从市售起始 原料仅需两步，无需中间纯化，且总产率 $>70 \%$.
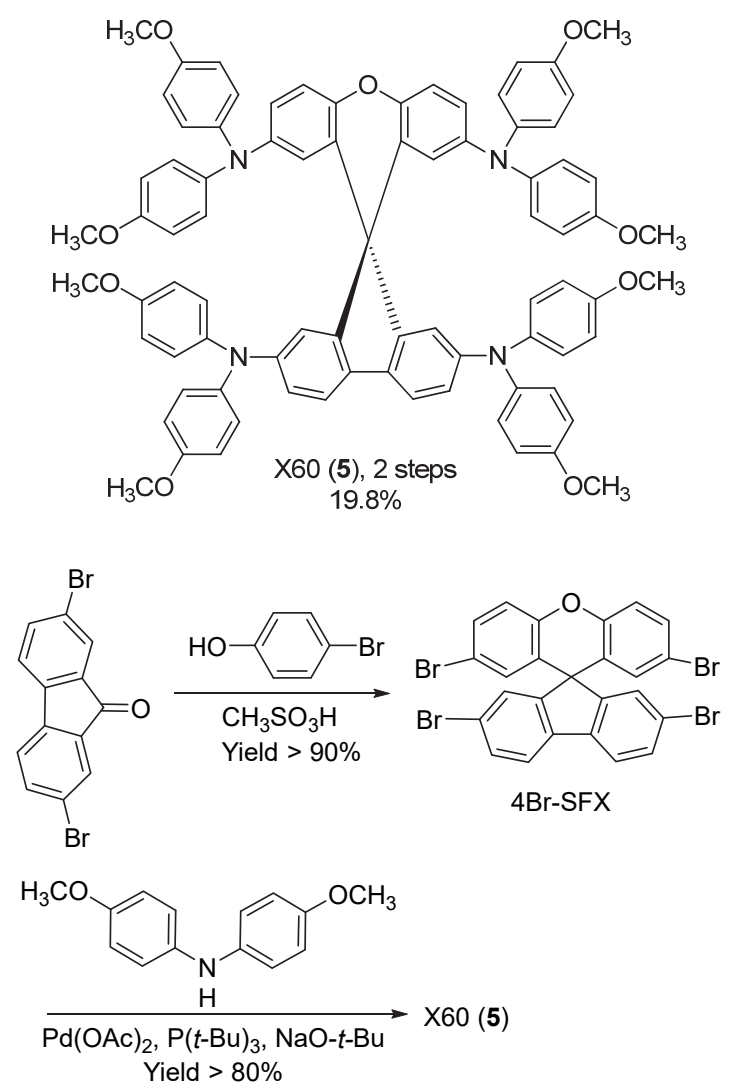

图式 3 X60 的合成路线

Scheme 3 Synthetic route of X60

X60 具有与 spiro-OMeTAD 相似的吸收和发射光谱, 而它的空穴迁移率(通过 SCLC 测量)为 $1.9 \times 10^{-4} \mathrm{~cm}^{2}$. $\mathrm{V}^{-1} \cdot \mathrm{s}^{-1}$, 相同条件下略高于 spiro-OMeTAD 的空穴迁移 率. 基于 $\mathrm{X} 60$ 的混合 $\left(\mathrm{FAPbI}_{3}\right)_{0.85}\left(\mathrm{MAPbBr}_{3}\right)_{0.15}$ 钙钛矿器 件在反向扫描条件下取得 $19.84 \%$ 能量转化效率, $V_{\mathrm{oc}}$ 为 $1.14 \mathrm{~V}, J_{\mathrm{sc}}$ 为 $24.2 \mathrm{~mA} \cdot \mathrm{cm}^{-2}, F F$ 为 0.71 , 与基于 spiroOMeTAD 的器件效率相当. 此外, 在基于 X60 的电池器 件中几乎没有观察到迟滞现象, 并且器件的光伏性能不 受扫速的影响.

为了进一步提高电池的“效率成本比”, 他们将 X60 
中的四个二苯胺基团减为两个, 设计了新的空穴传输材 料 X59 (6) ${ }^{[17]}$, 它可以通过与 X60 类似的两步反应制备 得到, 产率 $>80 \%$. X59 表现出与 spiro-OMeTAD 相似的 堆积方式. 基于 $\mathrm{FTO} / \mathrm{c}-\mathrm{TiO}_{2} / \mathrm{mp}-\mathrm{TiO}_{2} /$ 钻钛矿/X59/Au 的 器件取得 $19.8 \%$ 最高能量转换效率, 与在同一条件下制 备的基于 spiro-OMeTAD 的器件相当(20.8\%). 最重要的 是, 基于 X59 的器件在室温下(黑暗中)老化五周后表现 出较好的稳定性和可忽略的迟滞现象.

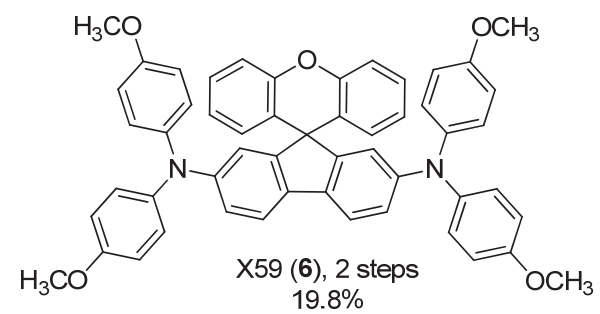

同时, 为了研究螺[芴-9,9'-氧杂葱]分子结构对器件 性能的影响, 孙立成和 Johansson 等 ${ }^{[18]}$ 通过使用一锅法 制备了含有三个 SFX 单元的三维低聚物 X55 (7). 与 Spiro-OMeTAD 相比, X55 具有更高的 HOMO 能级 $(-5.23 \mathrm{eV})$ 、更高的空穴迁移率 $\left(6.81 \times 10^{-4} \mathrm{~cm}^{2} \bullet \mathrm{V}^{-1} \bullet\right.$ $\left.\mathrm{s}^{-1}\right)$ 和电导率 $\left(8.43 \times 10^{-4} \mathrm{~S} \cdot \mathrm{cm}^{-1}\right)$ 以及更好的热稳定性 和成膜能力. 使用 X55 作为空穴传输材料的电池器件表 现出最高 $20.8 \%$ 的能量转化效率, 比相同条件下使用 Spiro-OMeTAD 的器件 $(\mathrm{PCE}=18.8 \%)$ 具有更好的性能. 基于 X55 的太阳能电池表现出出色的稳定性, 在长期老 化 6 个月后, 保留了初始效率的 $93 \%$.

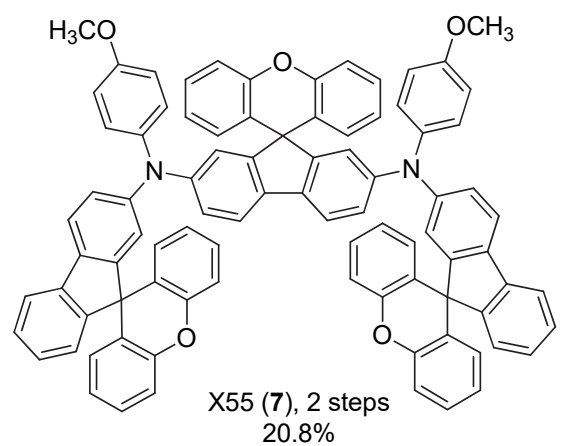

此外, 上述课题组还在 2018 年还报道了基于螺 [芴9,9'-氧杂葸]骨架的小分子材料 X26 (8) ${ }^{[19]}$, 并和以烷基 链为侧基的小分子材料 X22 作对比研究(图 4). 虽然 X22 的烷基链有利于提高分子的溶解度，但它可能会引 起分子间电荷传输的障碍. 具有多重螺环结构的 X26 在 有机溶剂(例如二氯甲烷和氯苯)中也显示出良好的溶解 性. 与 X22 相比, X26 具有更低的 HOMO 能级, 有利于 提高器件的开路电压. 基于 X26 的太阳能电池器件的最 高效率达到 $20.2 \%$, 而基于 X22 的器件只取得 $14.3 \%$ 效
率. X26 的高性能归因于它形成的薄膜均匀，从而导致 较少的电荷重组损失和较高的电荷提取. 此外, 三苯胺 分子上的侧基对钙钛矿薄膜的亲水性和润湿性有很大 影响, 基于 X26 的器件在室温/20\%湿度(在黑暗中)条件 下老化 5 个月后，能够保持 $>90 \%$ 的初始性能和 $18.8 \%$ 能量转化效率，显示出较好的长期稳定性.

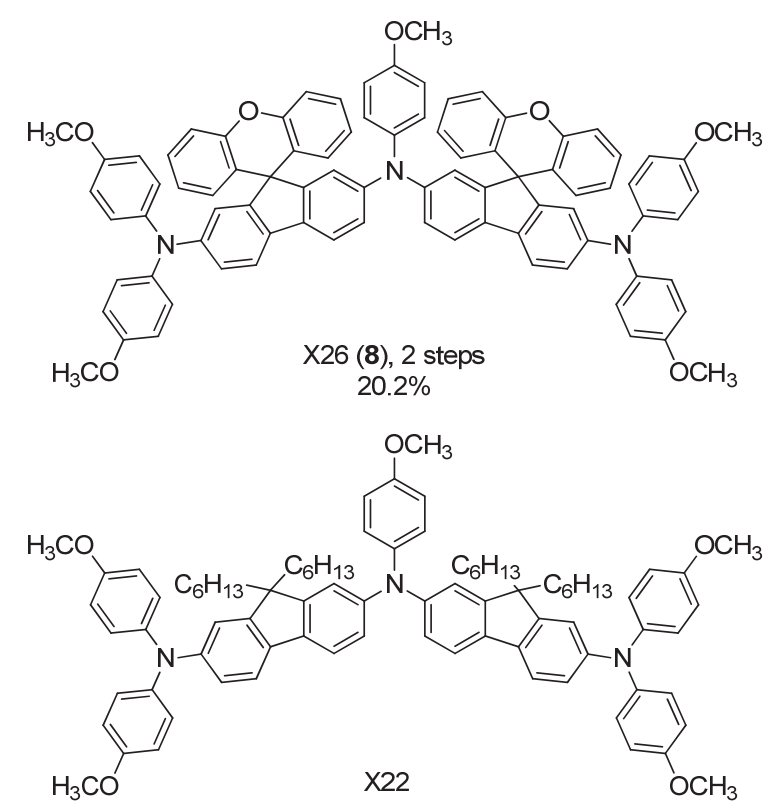

图 4 X26 (8) 的参比分子 X22 的结构式

Figure 4 Structure of the model compound X22 with respect to $\mathrm{X} 26(\mathbf{8})$

结合 $N^{3}, N^{6}$ - 双 (二-4- 茴香基氨基 )- $9 H$ - 咔唑 (DAnCBZ) 衍生物易于合成及成本低等优点, Seok 等 ${ }^{[20]}$ 合成了一种基于 $\mathrm{DAnCBZ}$ 的螺[芴-9,9'-氧杂葱]衍生物 SFXDAnCBZ (9), 其中心核和端基基团分别由 SFX 和 DAnCBZ 组成. SFXDAnCBZ 比 spiro-OMeTAD 更易于 合成，相应的合成成本更低. SFXDAnCBZ 的 HOMO 能 级(-4.95 eV)高于 spiro-OMeTAD, 并且它们具有相似 的玻璃化转变温度 $\left(T_{\mathrm{g}}=122{ }^{\circ} \mathrm{C}\right)$. SFXDAnCBZ 的空穴 迁移率为 $4.28 \times 10^{-4} \mathrm{~cm}^{2} \cdot \mathrm{V}^{-1} \cdot \mathrm{s}^{-1}$, 与 spiro-OMeTAD 相 当. 基于 SFXDAnCBZ 的器件的最高效率可以达到 $20.87 \%$.

目前，大多数超过 $20 \%$ 以上效率的器件都基于单螺 环分子，呈现垂直或正交构型，具有不同方向的电荷传 输能力. 与单螺环分子相比, 具有较大 $\pi$-环的双螺环共 轭体系可以赋予分子更高的刚度和结晶度，有利于提高 薄膜的空穴迁移率. 为了改善螺环分子的设计多样性, $\mathrm{Xie}$ 等[21]设计并合成了以双螺环为核心的 $\mathrm{H}$ 形分子 $\mathrm{G} 2$ (10). G2 由二螺环四溴化物和 4,4'-二甲氧基二苯胺通过 Hartwig-Buchwald 偶联反应合成，其中心核由 2,7-二溴 芴酮与 3,4-二溴噻吩反应制备得到. G2 分子显示出良好 的三维结构与较好的溶解度和成膜性能, 从而导致更少 


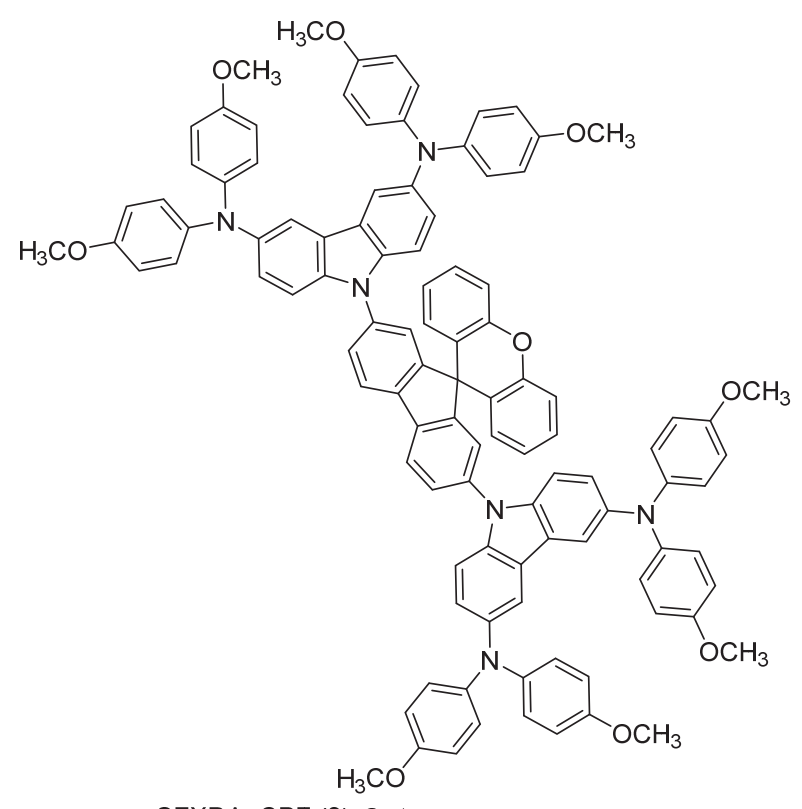

SFXDAnCBZ (9), 2 steps $20.87 \%$

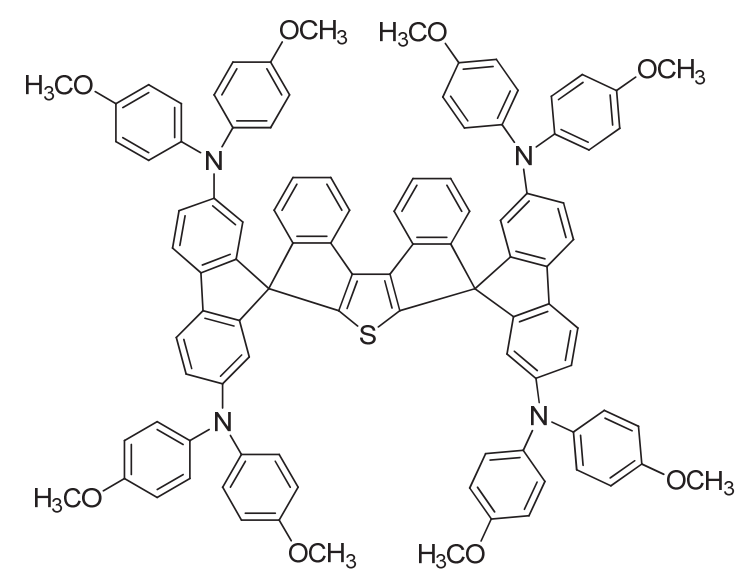

G2 (10), 3 steps

$20.2 \%$

的针孔结构和电流泄漏. 在 $100 \mathrm{~mW} \cdot \mathrm{cm}^{-2} \mathrm{AM} 1.5 \mathrm{G}$ 太 阳光下, 基于 $\mathrm{G} 2$ 器件的最高效率达到 $20.2 \%$. 经过三个 月的老化, 未封装器件性能几乎没有变化, 表明基于双 螺环的空穴传输材料具有良好的稳定性和巨大的潜力.

最近, Dar 等 ${ }^{[22]}$ 设计并合成了中心 $C_{2 v}$ 对称螺环构型 的空穴传输材料 HTM-1 (11). HTM-1 可以通过二澳螺环 戊二噻吩并呋啶和三芳胺硼酸酯经钯催化 Suzuki 偶联 反应合成(产率 $72 \%$ ), 其中二溴化物通过两步环化反应 和澳化反应制备得到. 与 spiro-MeOTAD 相比, HTM-1 具有更高的空穴迁移率 $\left(4.5 \times 10^{-4} \mathrm{~cm}^{2} \cdot \mathrm{V}^{-1} \cdot \mathrm{s}^{-1}\right)$ 、更高的 热稳定性和更好的水稳定性. 将 HTM-1 作为空穴传输 层用于 $(\mathrm{CsI})_{0.05}\left(\mathrm{FAPbI}_{3}\right)_{0.90}\left(\mathrm{MAPbBr}_{3}\right)_{0.10}$ (CsFAMA)钙钛 矿太阳能电池实现了 $21 \%$ 的最高效率、 $24.7 \mathrm{~mA} \cdot \mathrm{cm}^{-2}$ 的短路电流密度和 0.77 的高填充系数. 更重要的是, 基 于 HTM-1 的器件在连续照明 $400 \mathrm{~h}$ 和 $80{ }^{\circ} \mathrm{C}$ 的热稳定性
下均具有出色的长期稳定性, 这归因于其高的玻璃化转 变温度 $\left(T_{\mathrm{g}}=168{ }^{\circ} \mathrm{C}\right)$ 和出色的耐湿性.

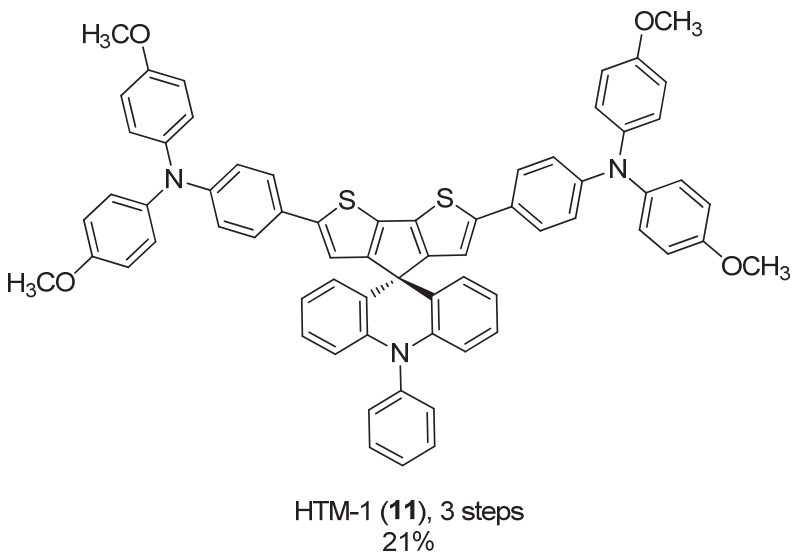

咔唑作为一种重要的富电子化合物, 其衍生物具有 出色的电荷传输能力, 并具有很高的热稳定性和形态学 稳定性，被广泛应用于合成空穴传输材料 ${ }^{[23]}$. 王照奎和 蒋佐权等 ${ }^{[24]}$ 将咔唑嵌段与螺环骨架优点相结合, 设计 合成了空穴传输材料 SCZF-5 (12) 和参比分子 SAF-5(图 5), 其中基于 SCZF-5 的器件效率最好为 $20.10 \%$, 显著 高于相同条件下基于 spiro-OMeTAD (19.11\%)和 SAF-5 (13.93\%) 的器件. 研究发现, 由于中心基团的不同, SCZF-5 比 SAF-5 具有更强的空穴输运能力和更低的 HOMO 能级. 另一方面, 与 spiro-OMeTAD 相比, SCZF5 保持了 spiro-OMeTAD 的空穴传输能力, 能调节能级 水平，从而提高了光伏性能. 此外，在 $30 \%$ 相对湿度下, 基于 SCZF-5 的器件比基于 spiro-OMeTAD 和 SAF- 5 的 器件具有更好的长期稳定性. 这些结果表明, 分子中心 结构的改变影响了薄膜的光电子特性和空穴迁移率, 从 而提高了光伏性能, 为设计新型空穴传输材料提供新思 路.

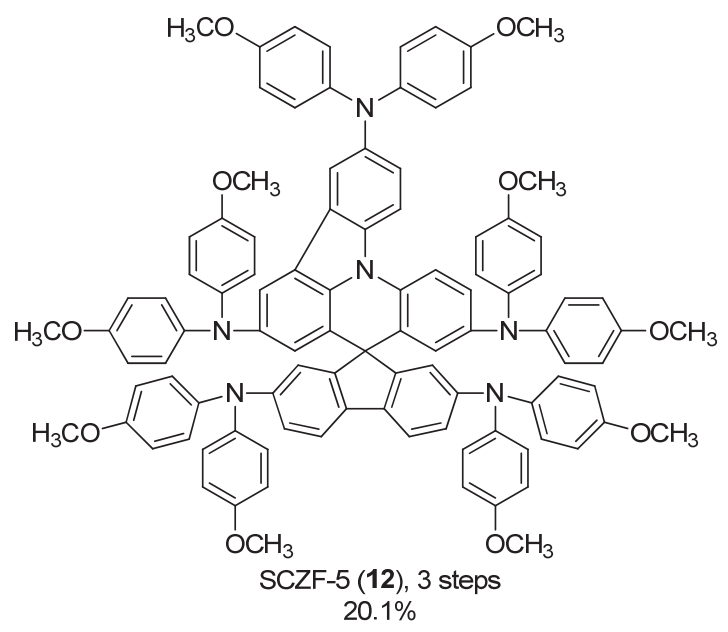

另外, 钲钛矿层的表面缺陷也会影响器件的迟滞和 稳定性. 研究者设计了许多针对表面缺陷针化的策略, 
包括使用路易斯酸/碱、卤化物盐、量子点及疏水性材料 等 ${ }^{25]}$. 例如, 利用硫原子(例如噻吩单元)或者路易斯碱 基团(例如羰基和氰基取代基)与钙钛矿中未配位 $\mathrm{Pb}^{2+}$ 离子的相互作用, 钝化钙钛矿层上的缺陷. 基于此, 高 鹏等[26]将路易斯碱引入 spiro-OMeTAD 的结构中, 这既 能保留 spiro-OMeTAD 的优点, 同时达到缺陷钝化的效 果. 通过简单的方法分别合成了含有双氰基取代螺环分 子 spiro-CN-OMeTAD (13). 该分子具有与钻钛矿相匹 配的 HOMO 能级 $(-5.16 \mathrm{eV})$ 、良好的成膜性能和空穴 迁移率 $\left(1.04 \times 10^{-3} \mathrm{~cm}^{2} \cdot \mathrm{V}^{-1} \cdot \mathrm{s}^{-1}\right)$. 基于 13 的平面 $\mathrm{n}-\mathrm{i}-\mathrm{p}$ 结构器件取得 $19.90 \%$ 最高能量转换效率和 $1.16 \mathrm{~V}$ 的高 开路电压和低迟滞现象.<smiles></smiles>

图 5 SCZF-5 (12)的参比分子 SAF-5 的结构式

Figure 5 Structure of the model compound SAF-5 with respect to SCZF-5 (12)

\section{2 含噻吩的有机小分子空穴传输材料}

除了螺环分子外, 含噻吩结构有机分子是另一类重<smiles>COc1ccc(N(c2ccc(OC)cc2)c2ccc3c(c2)C(=O)C(=C(C#N)C#N)c2cc(N(c4ccc(OC)cc4)c4ccc(OC)cc4)ccc2-c2cc(N(c4ccc(OC)cc4)c4ccc(OC)cc4)ccc2-3)cc1</smiles>

spiro-CN-OMeTAD (13), 3 steps $19.9 \%$

要的空穴传输材料. 噻吩是构建高空穴迁移率有机半导 体材料的一种优势基元，而且噻吩的硫原子和钻钛矿的 相互作用可以有效钝化钙钛矿表面的缺陷 ${ }^{[27]}$. 在上述 讨论的螺环结构分子中, FDT (3)、G2 (10)和 HTM-1 (11) 也使用了噻吩结构. 表 2 列举了含噻吩结构的有机小分 子空穴传输材料的能级、空穴迁移率及制备成电池的性 能参数.

王鹏等 ${ }^{[28]}$ 设计合成了并三噻吩桥联的双胺分子 $\mathrm{Z} 3$ (14). 该分子具有合适的 HOMO 能级 $(-5.24 \mathrm{eV})$ 和高的 空穴迁移率 $\left(2.4 \times 10^{-4} \mathrm{~cm}^{2} \cdot \mathrm{V}^{-1} \cdot \mathrm{s}^{-1}\right)$, 将其作为空穴传输 材料应用于钙钛矿太阳能电池时，实现 $20.84 \%$ 的能量 转换效率, 高于基于 spiro-OMeTAD 的参比器件效率 $(20.42 \%)$. 此外, 将 Z3 的并三噻吩桥基换成二甲基芴 时，所得到的双胺分子 Z2(图 6) 只取得 $15.40 \%$ 效率。一 方面，并三噻吩的使用提高了材料的结晶度并改善了电 荷载流子迁移率. 另一方面, 同时钙钛矿和 $\mathrm{Z} 3$ 之间较 强的界面相互作用有利于空穴提取.

表 2 不同空穴传输材料的能级及制备成电池的性能参数

Table 2 Energy levels of different HTMs and the performance parameters of the devices

\begin{tabular}{|c|c|c|c|c|c|}
\hline Device configuration & $\mathrm{HOMO} / \mathrm{el}$ & $\begin{array}{l}\text { Hole mobility } \\
\left(\mathrm{cm}^{2} \cdot \mathrm{V}^{-1} \cdot \mathrm{s}^{-1}\right)\end{array}$ & 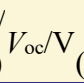 & $\begin{array}{c}J_{\mathrm{sc}} / \\
\left.\mathrm{A} \cdot \mathrm{cm}^{-2}\right)\end{array}$ & FF PCE $\%$ Ref. \\
\hline 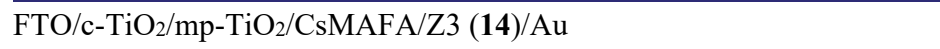 & -5.24 & $2.4 \times 10^{-4}$ & 1.12 & 25.1 & $0.7520 .84[21]$ \\
\hline 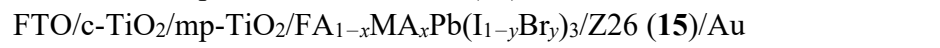 & -5.16 & $1.34 \times 10^{-4}$ & 1.13 & 23.6 & $0.7520 .10[29]$ \\
\hline 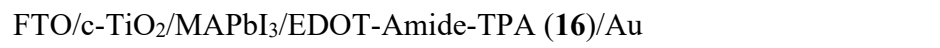 & -5.23 & $3.9 \times 10^{-5}$ & 1.16 & 22.7 & $0.7720 .30[30]$ \\
\hline 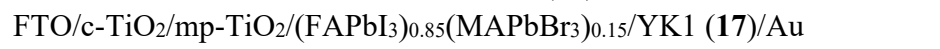 & -5.19 & $6.68 \times 10^{-4}$ & 1.11 & 23.55 & $0.7720 .13[31]$ \\
\hline $\mathrm{ITO} / \mathrm{SnO}_{2} /\left(\mathrm{FAPbI}_{3}\right)_{0.95}\left(\mathrm{MAPbBr}_{3}\right)_{0.05} / \mathrm{TTE}-2(\mathbf{1 8}) / \mathrm{Au}$ & -5.30 & $6.18 \times 10^{-4}$ & 1.11 & 23.26 & $0.7720 .04^{a}[32]$ \\
\hline $\mathrm{ITO} / \mathrm{SnO}_{2} / \mathrm{CsMAFA} / \mathrm{OMe}-\mathrm{TATPyr}(\mathbf{1 9}) / \mathrm{Au}$ & -5.4 & $2.28 \times 10^{-4}$ & 1.10 & 23.3 & $0.8120 .60[34]$ \\
\hline $\mathrm{FTO} / \mathrm{SnO}_{2} / \mathrm{C}_{60} / \mathrm{MA}_{0.7} \mathrm{FA}_{0.3} \mathrm{~Pb}\left(\mathrm{I}_{0.925} \mathrm{Br}_{0.075}\right)_{3} / \mathrm{DTP}-\mathrm{C} 6 \mathrm{Th}(\mathbf{2 0}) / \mathrm{Au}$ & -4.94 & $4.18 \times 10^{-4}$ & 1.16 & 22.76 & $0.8021 .04^{a}[35]$ \\
\hline $\mathrm{FTO} / \mathrm{SnO}_{2} / \mathrm{C}_{60} / \mathrm{FA}_{1-x} \mathrm{MA}_{x} \mathrm{~Pb}\left(\mathrm{I}_{1-y} \mathrm{Br}_{y}\right)_{3} / \mathrm{PMMA} / \mathrm{DTPC} 8-\mathrm{ThDTPA}(\mathbf{2 1}) / \mathrm{Au}$ & -4.85 & $6.5 \times$ & 1.14 & 23.02 & $0.7419 .42^{a}[36]$ \\
\hline $\mathrm{ITO} / \mathrm{SnO}_{2} / \mathrm{CsMAFA} / \mathrm{M} 129(\mathbf{2 2}) / \mathrm{Au}$ & -5.15 & $4.23 \times 10^{-4}$ & 1.12 & 23.3 & .35 [37] \\
\hline ITO/DBTMT (23)/MAPbI $3 / \mathrm{C}_{60} / \mathrm{BCP} / \mathrm{Ag}$ & -5.02 & & 1.12 & 22.7 & $0.8321 .12[38]$ \\
\hline $\mathrm{ITO} / \mathrm{SnO}_{2} / \mathrm{CsFAMA} / \mathrm{BTTI}-\mathrm{C} 6(\mathbf{2 4}) / \mathrm{Au}$ & -5.25 & $2.19 \times 10^{-4}$ & 1.10 & 23.41 & $0.7519 .69^{a}[39]$ \\
\hline ITO/BDT-POZ (25)/MAPbI $3 / \mathrm{PCBM} / \mathrm{BCP} / \mathrm{Ag}$ & -4.83 & $2.1 \times 10^{-4}$ & 1.04 & 22.56 & $0.8219 .16^{a}[40]$ \\
\hline $\mathrm{ITO} / \mathrm{SnO}_{2} / \mathrm{FA}_{0.85} \mathrm{MA}_{0.15} \mathrm{PbI}_{3} / \mathrm{SM} 2(\mathbf{2 6}) / \mathrm{MoO}_{3} / \mathrm{Ag}$ & -5.42 & $4.51 \times 10^{-4}$ & 1.07 & 24.5 & $0.7920 .56[41]$ \\
\hline $\mathrm{FTO} / \mathrm{c}-\mathrm{TiO}_{2} / \mathrm{mp}_{-} \mathrm{TiO}_{2} /\left(\mathrm{FAPbI}_{3}\right)_{0.85}\left(\mathrm{MAPbBr}_{3}\right)_{0.15} / \mathrm{KR}_{32} 1(\mathbf{2 7}) / \mathrm{Au}$ & -5.24 & $2.6 \times 10^{-4}$ & 1.13 & 21.7 & $0.7819 .03[42]$ \\
\hline
\end{tabular}

${ }^{a}$ Dopant-free. 

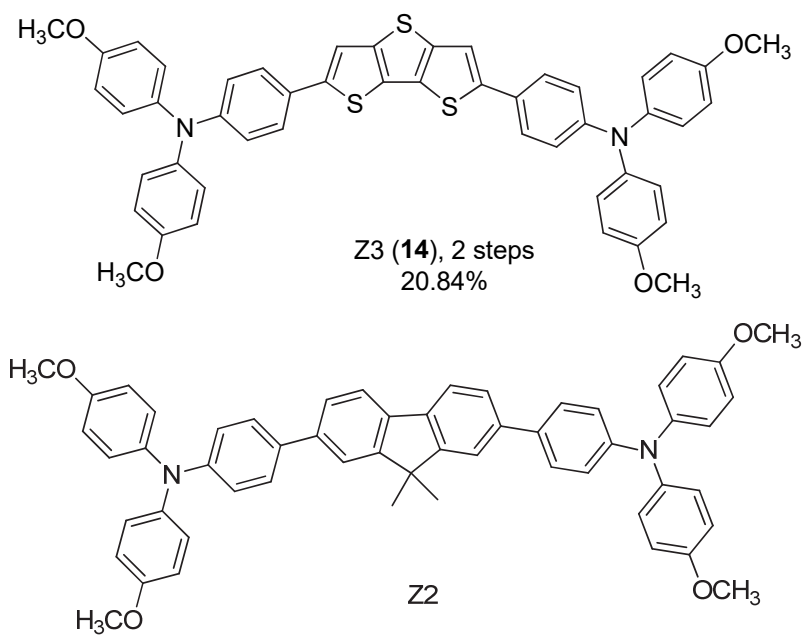

图 $6 \mathrm{Z} 3(\mathbf{1 4})$ 的参比分子 $\mathrm{Z} 2$ 的结构式

Figure 6 Structure of the model compound Z2 with respect to Z3 (14)

李祥高等 ${ }^{[29]}$ 在 2017 年合成了基于噻吩核的空穴传 输材料 Z26 (15). Z26 通过相应的噻吩二醛和三芳胺磷 酸酯衍生物经 Horner-Wadsworth-Emmons 反应制备得 到, 实验室制备成本 $35.57 \mathrm{\$} \cdot \mathrm{g}^{-1}$, 比 spiro-OMeTAD 低 很多(Scheme 4). 基于 Z26 的器件实现最高 20.1\%的能 量转化效率, 接近基于 spiro-OMeTAD 获得的 20.6\%效 率. 此外, 不含双键的参比分子 Z25 (Scheme 4) 只取得 $16.9 \%$ 的效率. 研究表明, 双键的引入可以改善材料的 成膜性能, 并提高空穴迁移率 $\left(1.34 \times 10^{-4} \mathrm{~cm}^{2} \cdot \mathrm{V}^{-1} \bullet \mathrm{s}^{-1}\right)$ 和电导率 $\left(2.1 \times 10^{-4} \mathrm{~S} \cdot \mathrm{cm}^{-1}\right)$. 与 Z25 和 spiro-OMeTAD 相比, 基于 Z26 的器件也表现出更好的稳定性, 表明双 键基团在有机功能分子设计中具有独特作用. 为了进一 步降低制备成本简化合成步骤，Petrus 课题组 ${ }^{[30]}$ 报道了 一种结构类似的空穴传输材料 EDOT-Amide-TPA (16), 胺基基团通过酰胺键与噻吩桥基相连, 实验室制备成本 仅为 $5 \$ \mathrm{~g}^{-1}$. 将其用作钙钛矿太阳能电池的空穴传输层 时, 可以获得 $20.3 \%$ 的效率和 $20.0 \%$ 的稳定功率输出. 作者认为 EDOT-Amide-TPA 中酰胺键与锂离子具有一 定的配位能力, 克服了由添加剂迁移引起的降解, 从而 提高了器件的稳定性.

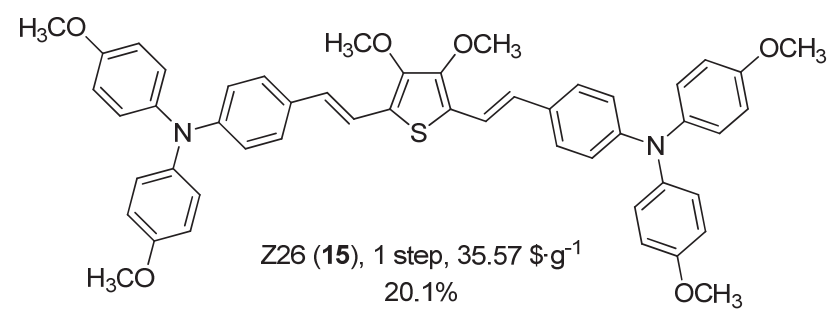

华雍课题组 ${ }^{[31]}$ 基于狮并二噻吩(IDT)骨架合成了 $N^{3}, N^{6}$-双(二-4-茴香基氨基)- $9 H$-咔唑封端的空穴传输材<smiles>CCOP(=O)(Cc1ccc(N(c2ccc(OC)cc2)c2ccc(OC)cc2)cc1)OCC(C)(C)C</smiles><smiles>COc1ccc(N(c2ccc(OC)cc2)c2ccc(-c3sc(-c4ccc(N(c5ccc(OC)cc5)c5ccc(OC)cc5)cc4)c(OC)c3OC)cc2)cc1</smiles>

图式 4 Z26 (15)的合成路线和参比分子 Z25 的结构 Scheme 4 Synthetic route of Z26 (15) and the structure of the model compound Z25

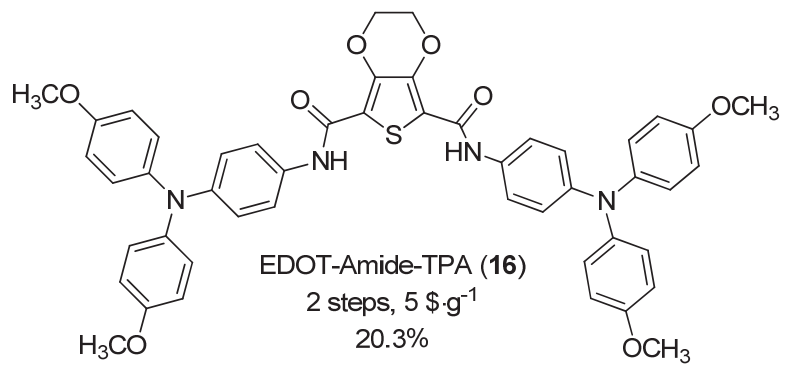

料 YK1 (17). IDT 的共轭平面骨架和 IDT 单元中易极化 的硫原子的存在有利于 YK1 形成分子间 $\pi-\pi$ 堆叠，增强 材料的电导率和电荷传输. 此外, 在共轭骨架上引入己 基苯基基团可以有效增强溶解性和疏水性，实现高质量 的薄膜制备并增强器件的环境稳定性. 基于 YK1 的电 池器件取得了 $20.13 \%$ 的能量转化效率, 高于同一条件 下基于 Spiro-OMeTAD 的器件 $(\mathrm{PCE}=19.01 \%)$. 此外, 作者改变了 YK1 的双(二-4-茴香基氨基)的取代位置, 制 备了参比分子 YK2(图 7, 在咔唑的 2,7-位取代), 相应的 器件效率只有 $17.35 \%$. 与 YK2 相比, YK1 分子在咔唑的 3,6-位含有胺基取代，有利于形成有效的分子间 $\pi-\pi$ 堆 积以及合适的 HOMO 水平和更高的空穴迁移率，表明 胺基取代基的位置对太阳能电池性能有重要影响.

四噻吩乙烯(TTE) 是一种常见的聚集诱导发色团. 朱为宏和吴永真等 ${ }^{[32]}$ 设计合成了两个基于四噻吩乙烯 的空穴传输材料 TTE-1 和 TTE-2 (18), 两者的区别在于 TTE-2 中两个噻吩基团通过碳-碳单键锁定，与乙烯基 团形成平面苯并二噻吩结构(图 8). TTE-1 展现出类似于 spiro-OMeTAD 的正交构象，而 TTE-2 表现为平面/正交 杂化构象. 虽然 TTE-1 和 TTE-2 结构差别很小, 但其性 质发生了明显变化. TTE-2 的空穴迁移率为 $6.18 \times 10^{-4}$ 


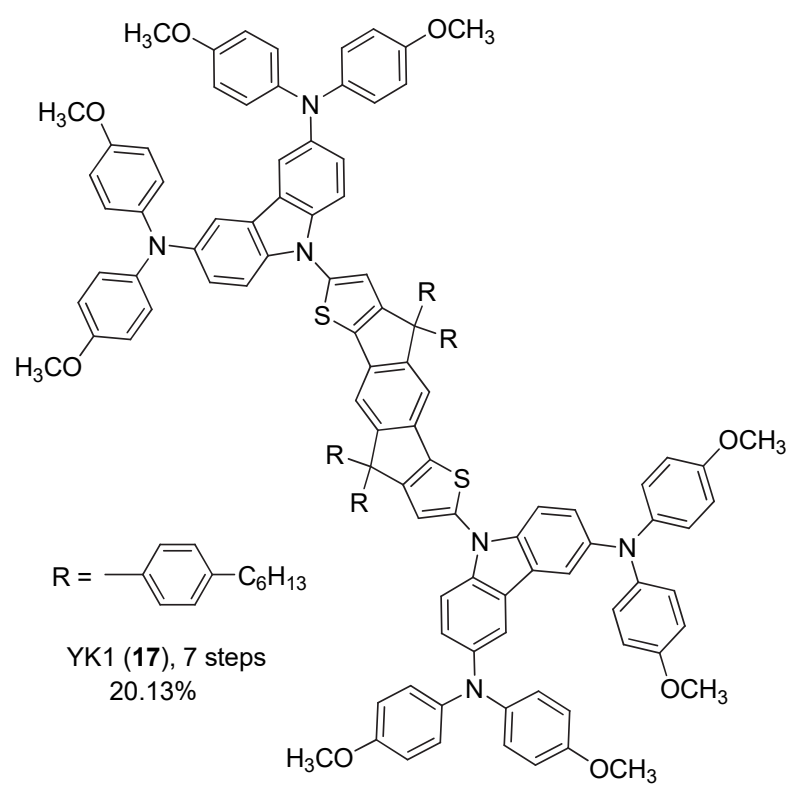<smiles>[R]=Cc1ccc(CCCCCC)cc1</smiles>

图 7 YK1 (17)的参比分子 YK2 的结构式

Figure 7 Structure of the model compound YK2 with respect to YK1 (17)<smiles>COc1ccc(N(c2ccc(OC)cc2)c2ccc(-c3ccc(-c4c5sc(-c6ccc(N(c7ccc(OC)cc7)c7ccc(OC)cc7)cc6)cc5c5cc6c7ccccc8ccc(N(c9ccc(OC)cc9)c9ccc(OC)cc9)sc(cc6sc45)-c8cc7)s3)cc2)cc1</smiles>

$\mathrm{cm}^{2} \cdot \mathrm{V}^{-1} \cdot \mathrm{s}^{-1}$. 基于非掺杂 TTE-2 器件的最高能量转换效 率为 $20.04 \%$. 相比较, TTE-1 的空穴迁移率为 $8.70 \times$ $10^{-5} \mathrm{~cm}^{2} \cdot \mathrm{V}^{-1} \cdot \mathrm{s}^{-1}$, 器件效率只有 $13.68 \%$. 如果四个噻吩 基团被完全锁定，所得到的高平面分子显示出非常低的 溶解度，不利于合成和溶液法制备薄膜. 该工作表明通 过调控空穴传输材料的分子构型, 可以实现迁移率和薄 膜形貌的平衡，并达到优化器件性能的目的.

前期研究结果表明，基于萠的三芳胺衍生物是一种 潜在的优良空穴传输材料 ${ }^{[33]}$. 受此启发, 我们课题组和 合作者 ${ }^{[34]}$ 一起合成了有机小分子空穴传输材料 OMeTATPyr (19), 它可以通过简短的合成步骤实现克级制 备, 实验室制备成本约为 $50 \$ \mathrm{~g}^{-1}$. OMe-TATPyr 通过苯 基噻吩连接中心萠核和三芳胺端基基团形成星形分子 结构，这种结构被认为有利于通过有效的离域和分子间 堆积来增强空穴载流子迁移率. 此外, 苯基噻吩单元的 引入有利于通过 $\mathrm{Pb} / \mathrm{S}$ 相互作用钝化钙钛矿的界面缺陷, 并改善电荷传输分子的电荷离域度和迁移率. 基于

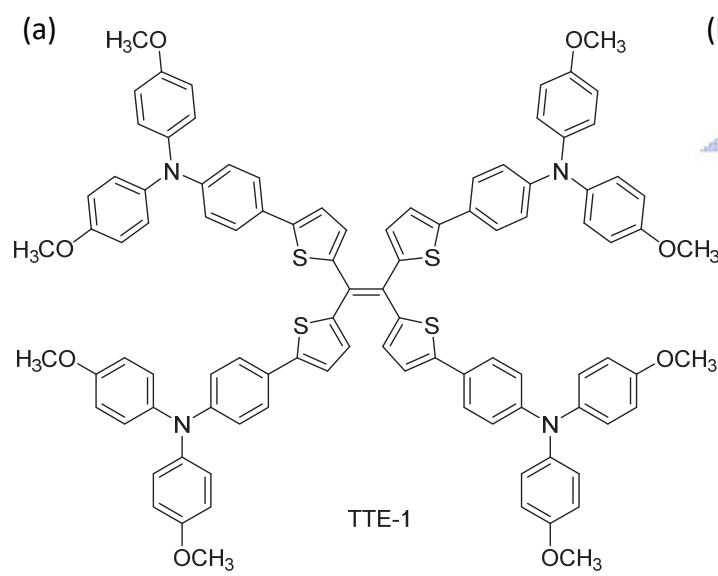

b)

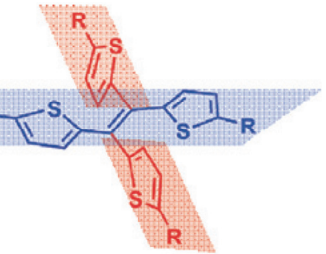

正交 (TTE-1)

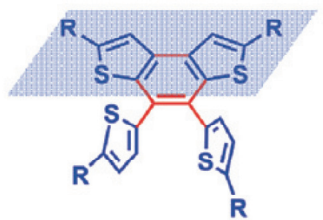

平面/正交杂化（TTE-2）

图 8 (a) TTE-2 (18)的参比分子 TTE-1 的结构式和(b) TTE-1 和 TTE-2 的构型示意图

Figure 8 (a) Structure of the model compound TTE-1 with respect to TTE-2 (18) and (b) schematic representation of the geometrical configurations of TTE-1 and TTE-2 
OMe-TATPyr 的电池器件最高能量转换效率可以达到 $20.6 \%$, 平均效率为 $20.0 \%$, 并且具有良好的稳定性.

双噻吩吡咯(DTP)具有较好的给电子能力、良好的 共面性、高迁移率以及易于调整的能级, 被广泛用于有 机功能分子的设计中. 跒炎发和唐卫华等 ${ }^{[35]}$ 以 DTP 为 核心, 噻吩为桥联基团和三芳胺为端基基团构建了一种 新型的非掺杂空穴材料 DTP-C6Th (20). 其中, 引入噻 吩单元不仅可以增大 $\pi$ 共轭, 还可以利用噻吩中的硫原 子与钙钛矿中的碘/铅离子之间发生更强的相互作用. DTP-C6Th 由含有 DTP 结构的锡试剂和三芳胺衍生物通 过钯催化的 Stille 偶联反应合成得到, 其实验室合成的 成本估计约为 $30 \$ \cdot \mathrm{g}^{-1}$. 与经典的 spiro-OMeTAD 相比, DTP-C6Th 表现出相似的能级、更好的空穴迁移率 4.18 $\left.\times 10^{-4} \mathrm{~cm}^{2} \cdot \mathrm{V}^{-1} \cdot \mathrm{s}^{-1}\right)$ 以及更高的空穴提取效率. 使用非 掺杂 DTP-C6Th 作为空穴传输材料的平面钲钛矿器件取
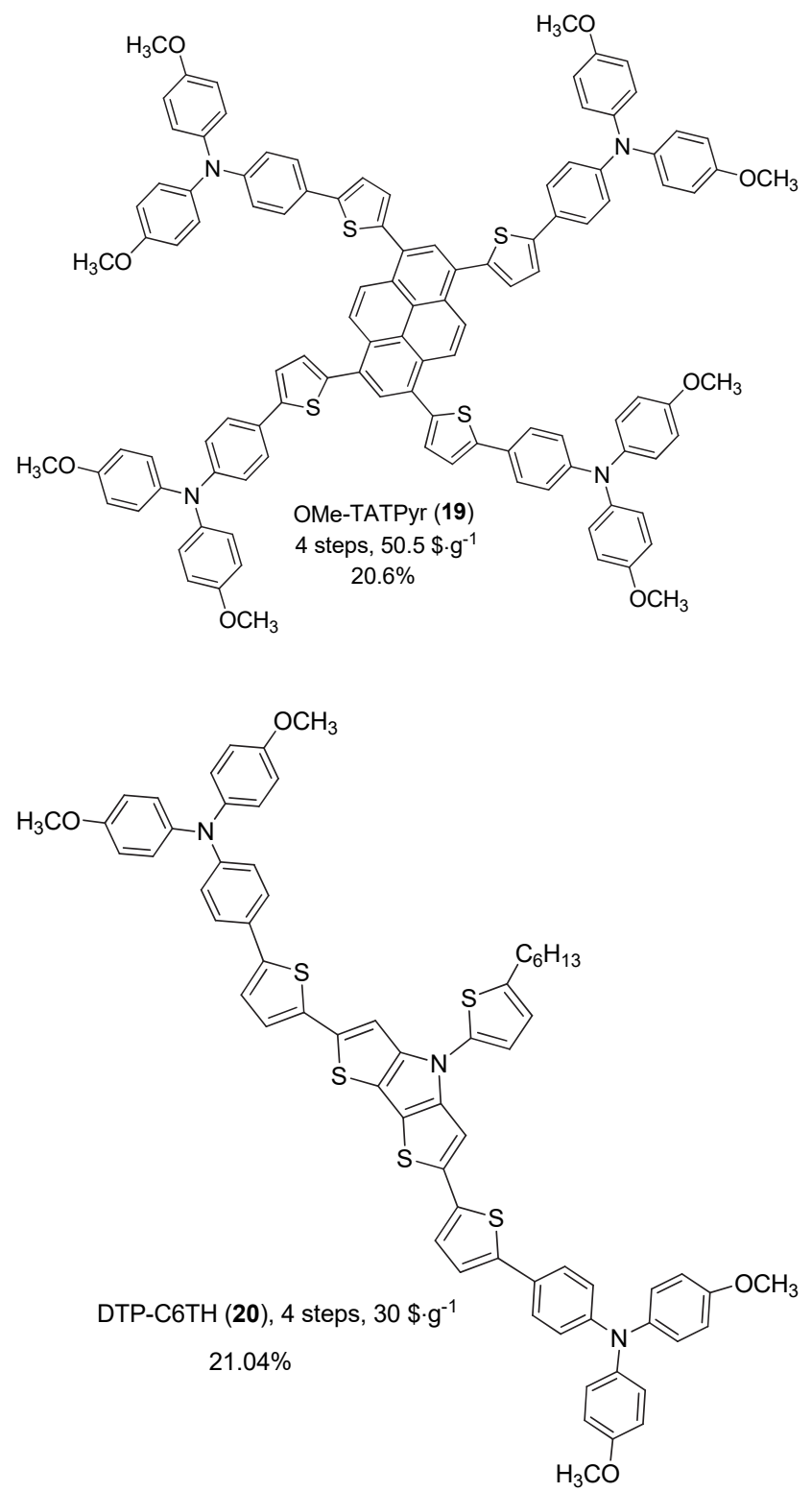

得 18.56\%的效率. 通过添加超薄的聚(甲基丙烯酸甲酯) 钝化层并适当调整钙钛矿吸收剂层的组成, 可获得 $21.04 \%$ 的效率和 $20.36 \%$ 的稳态输出. 未封装的 DTPC6Th 器件在氮气充填的手套箱中存放时, 其性能下降 可忽略不计, 并且在相对湿度约为 $35 \%$ 的空气中存放 $60 \mathrm{~d}$ 后, 其效率还能保持初始 $85 \%$ 以上. 相比之下, 基 于 spiro-OMeTAD 的器件在空气和惰性气氛中均显示出 明显的效率下降. 此外, 他们 ${ }^{[36]}$ 制备了双噻吩吡咯桥联 的含有四个三芳胺端基基团的星形分子 DTPC8ThDTPA (21). 将非掺杂 DTPC8-ThDTPA 应用于钻钛矿 $\left(\mathrm{MA}_{0.7} \mathrm{FA}_{0.3} \mathrm{PbI}_{2.85} \mathrm{Br}_{0.15}\right)$ 器件中, 取得最高 $19.42 \%$ 能量转 换效率, 与掺杂的 spiro-OMeTAD 器件效率相当 (19.59\%). 与此同时，梁茂和吴永真等 ${ }^{[37]}$ 制备了双噻吩 吡咯桥联的有机空穴传输材料 M129 (22), 其端基基团 为咔唑-芴杂化的茚并咔唑基团. 基于 M129 的器件在 掺杂和非掺杂条件下分别实现了 $20.35 \%$ 和 $17.50 \%$ 的能 量转化效率. 相比较, 如果使用咔唑、芴或者甲氧基取 代三苯胺为端基基团时, 相应的器件效率要低很多, 为 设计新型无甲氧基空穴传输材料提供新的方向和思路.
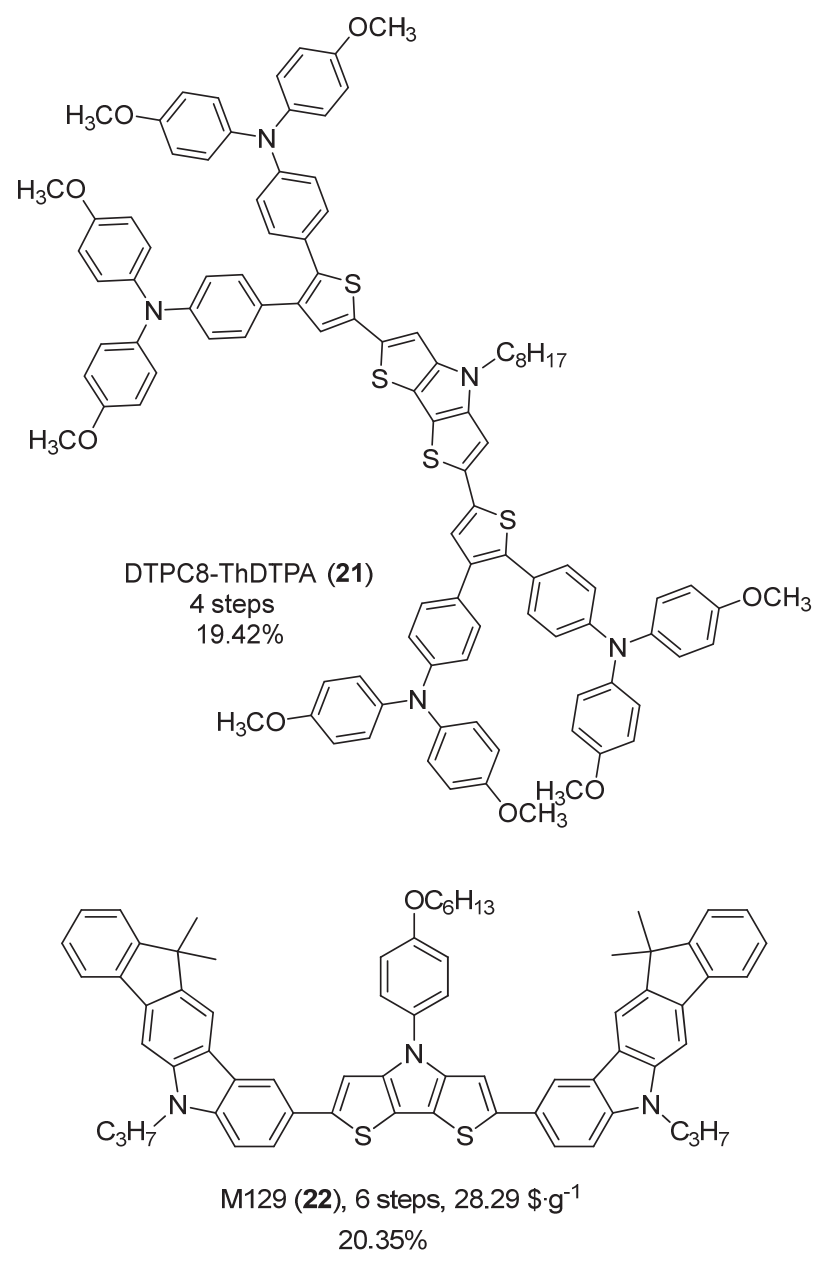

最近，袁宁一和李永舫等 ${ }^{[38]}$ 报道了一种甲硫基取 
代的线性二苯并噻吩分子 DBTMT (23), 以二苯并噻吩 为中心核和双(4-(甲硫基)苯基)胺为端基基团. DBTMT 通过 Buchwald-Hartwig 一步反应合成，产率为 76.9\%， 其合成成本估计约为 $47 \$ \mathrm{~g}^{-1}$. DBTMT 具有良好的热稳 定性, HOMO 和最低空分子轨道(LUMO)能级之间的重 叠有利于增强 DBTMT 分子的空穴传输. 通过 DBTMT 中的硫原子与钻铁矿的相互作用, 可以针化界面处的缺 陷, 从而改善结晶度. 基于非掺杂 DBTMT 的钙钛矿太 阳能电池(结构为 $\mathrm{ITO} / \mathrm{DBTMT} / \mathrm{MAPbI}_{3} / \mathrm{C}_{60} / \mathrm{BCP} / \mathrm{Ag}$ ) 的 最高能量转换效率达到 $21.12 \%$, 填充因子为 $83.25 \%$. 相比之下, 在相同条件下使用 PTAA 作为空穴传输材料 的器件效率为 $17.39 \%$.

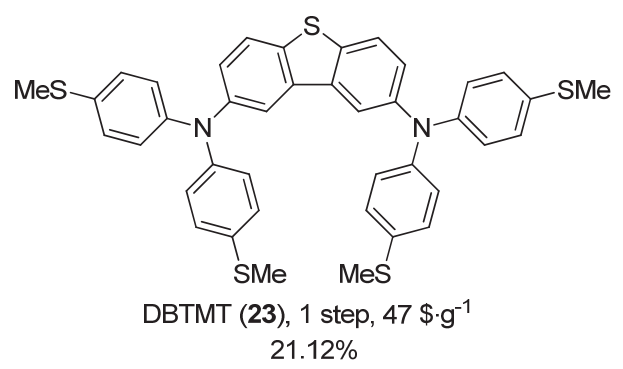

何祝兵和郭旭岗等 ${ }^{[39]}$ 以联噻吩酸䣶作为起始原料, 通过酰亚胺化、澳化和 Suzuki 偶联的三步反应得到噻吩 酰胺桥联的二胺化合物 BTTI-C6 (24). 将 BTTI-C6 作为 非掺杂空穴传输材料时, 电池器件效率可达 $19.69 \%$. 研 究发现, 将酰胺氮原子的烷基链 $\mathrm{C}_{6} \mathrm{H}_{13}$ 换成 $\mathrm{C}_{8} \mathrm{H}_{17}$ 或 $\mathrm{C}_{12} \mathrm{H}_{25}$ 时, 相应分子作为应用电池器件时, 效率下降至 18.89\%和 $17.49 \%$, 表明分子烷基链的长短对电池性能 也有较大的影响. 虽然具有不同侧链长度的分子显示出 相似的光物理和电化学性质, 随着侧链长度的减少, 空 穴迁移率、成膜能力和所得器件性能得到了改善.

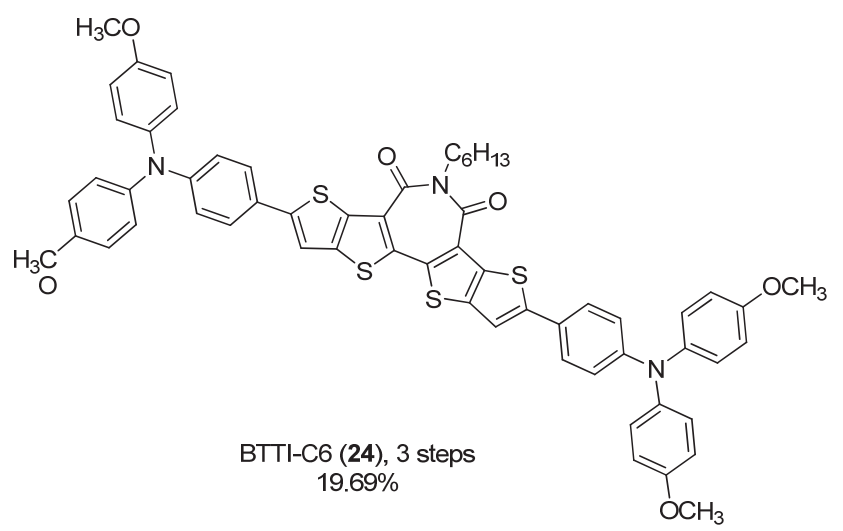

上述小分子材料大部分使用甲氧基取代的三芳胺 或咔唑衍生物为端基基团. 甲氧基的存在提供了一个和 钙铁矿相互作用以及空穴传输的途径. 此外, 甲氧基使 空穴传输材料易于氧化, 从而提高高空穴迁移率. 但是
甲氧基的强给电子能力可能会降低分子的氧化电位，从 而导致开路电压的损失. 而且甲氧基的存在也会增加薄 膜的亲水性, 从而不利于器件的稳定性. 上文讨论的狮 并咔唑基团封端的空穴传输材料 M129 (22) 就是一个不 含甲氧基的一个特殊例子. 除此之外，蔡宁等 ${ }^{[40]}$ 在 2019 年报道了以 4,8 二 二(己硫基)-苯并二噻吩(BDT)作为 $\pi$-共 轭连接体, $N$-(6-溴已基)吩嗪(POZ)为端基基团的空穴传 输材料 BDT-POZ (25). 在 BDT 单元中引入稠合噻吩基 团的目的是提高分子共轭骨架的给电子能力, 以增加空 穴迁移率以及电子离域程度. 此外, 由于溴已基的引入 有利于增强分子之间偶极-偶极相互作用，促进材料的 有序组装. 同时，由于溴原子周围存在孤对电子，可以 通过溴己基作为路易斯碱与钙钛矿中的 $\mathrm{Pb}^{2+}$ 离子配位 实现有效的缺陷钝化. 将 BDT-POZ 作为非掺杂空穴传 输材料应用于钙铁矿电池器件时, 实现了 $19.16 \%$ 的能 量转换效率，同时具有较小的迟滞现象.

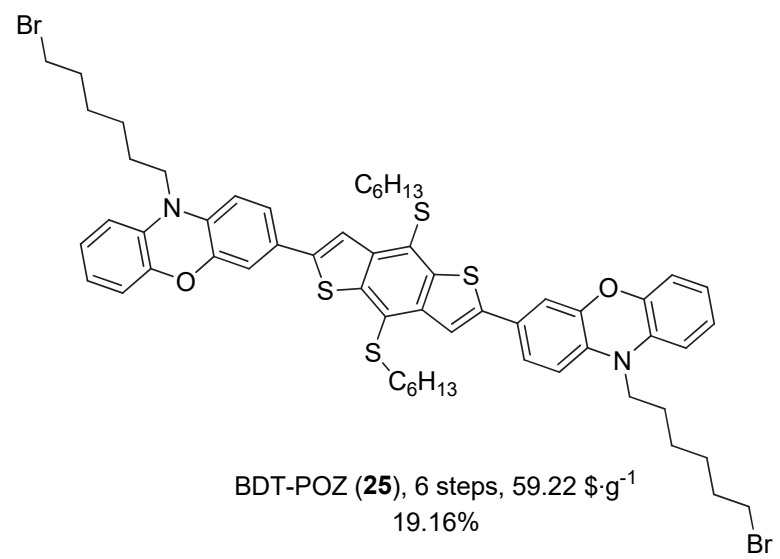

除了使用不同封端基团之外，设计、合成给-受体类 型分子也是避免使用甲氧基封端基团的一种方法. 例 如, Lee 等 ${ }^{[41]}$ 合成了基于苯并二噻吩给体和 $N$-乙基绕丹 宁受体的 A-D-A 类型空穴传输材料 SM2 (26). 基于非 掺杂 SM2 的电池器件可以实现 $20.56 \%$ 的效率. 在 $8{ }^{\circ} \mathrm{C}$ 和 $85 \%$ 相对湿度的环境条件下，基于 SM2 的器件在 100 $\mathrm{h}$ 内保持其初始效率的 $80 \%$ 以上. 研究还表明，当将 $\mathrm{SM} 2$ 结构中噻吩上的 $\mathrm{R}$ 取代基从 $\mathrm{C}_{6} \mathrm{H}_{13}$ 换成 “ $\mathrm{H}$ ”后，所 得到的 SM1 分子作为空穴传输材料只取得 $15.37 \%$ 的效 率. 烷基链的使用，提高了 SM2 的溶解度并有效地控制 了分子的堆积/排列和取向, 增强了电荷转移/传输以及 抑制载流子的重组. 烷基链长短对器件性能影响在上文 讨论的 BTTI-C6 (24)材料中也有所体现.

Nazeeruddin 等[42]设计了一种新型的非掺杂的星形 $D-\pi-A$ 型空穴传输材料 KR321 (27), 它通过三联噻吩连 接具有平面的三氮杂三聚荫中心核给体和丙二腈端基 受体构成. 由于强的分子间相互作用，该分子易形成面 


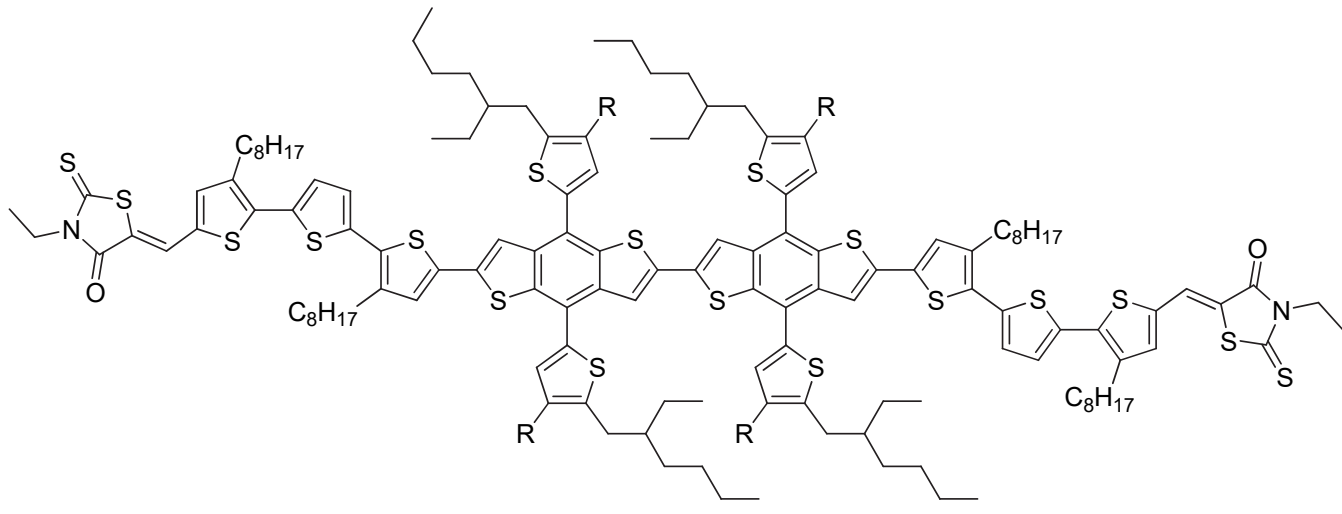

SM2 (26), $\mathrm{R}=\mathrm{C}_{6} \mathrm{H}_{13}, 6$ steps

$20.56 \%$

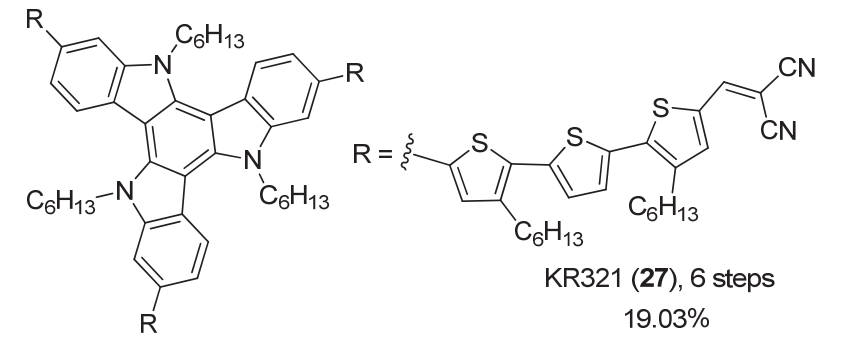

面柱状堆积, 具有高电荷载流子迁移率 $\left(2.6 \times 10^{-4}\right.$ $\mathrm{cm}^{2} \cdot \mathrm{V}^{-1} \cdot \mathrm{s}^{-1}$ ), 可最大程度地减少接触的欧姆损耗. 此 外, 它结合了小分子(即多孔结构)和聚合物(如良好的热 化学、电化学和光化学稳定性)的优点, 且溶解度高, 对 䥻钛矿的润湿性好. 使用非掺杂 KR321 作为空穴传输 材料应用于 $\left(\mathrm{FAPbI}_{3}\right)_{0.85}\left(\mathrm{MAPbBr}_{3}\right)_{0.15}$ 钙铁矿太阳能电 池, 可以实现 $19 \%$ 以上的效率 $\left(V_{\mathrm{oc}}\right.$ 为 $1.13 \mathrm{~V}, J_{\mathrm{sc}}$ 为 21.70 $\mathrm{mA} \cdot \mathrm{cm}^{-2}, \mathrm{FF}$ 为 $78 \%$ ), 与掺杂 spiro-OMeTAD 的器件效 率基本一样(19.01\%). 另外, 基于非掺杂 KR321 的器件 稳定性得到了显著提高, KR321 在老化 $650 \mathrm{~h}$ 后仍保持 了其初始 PCE 的 $60 \%$, 而在相同条件下使用掺杂的 spiro-OMeTAD 的器件的效率下降了 $80 \%$.

\section{3 其他有机小分子空穴传输材料}

上述含有螺环结构和噻吩基团的小分子是两类已 经报道的主要高性能有机空穴传输材料. 除此之外, 研 究者近期也发展了诸多其他结构的有机小分子空穴传 输材料. 表 3 列举了相应的能级、空穴迁移率及制备成 电池的性能参数.

叶轩立和朱琳娜等 ${ }^{[43]}$ 合成了一种甲硫基封端的基 于四苯基乙烯骨架的小分子 TPE-S (28), 通过 1,1,2,2-四 (4-溴苯基)乙烯与甲硫基二苯胺之间的 BuchwaldHartwig 反应得到. TPE-S 分子呈现高度扭曲结构, 有利 于减弱分子间的相互作用. 与其他文献报道的 TPE 空穴 传输材料相比, 在 TPE 分子上引入了硫原子来代替常规 使用的氧原子, 通过硫原子与钙钛矿的 $\mathrm{Pb}^{2+}$ 离子形成配
位键而提供了有效的表面钝化效果, 显著影响沉积在顶 部的钙钛矿膜的结晶并有效抑制了界面重组. 基于非掺 杂 TPE-S 的全无机 $\mathrm{CsPbI}_{2} \mathrm{Br}$ 器件表现出了 $15.4 \%$ 的能量 转换效率, 并具有 $14.3 \%$ 的稳定功率输出. 同时将 TPE-S 作为空穴传输材料应用于混合 $\mathrm{FA}_{0.9} \mathrm{Cs}_{0.1} \mathrm{PbI}_{3}$ 的反 式器件中, 取得了 $21.0 \%$ 的能量转换效率. 器件良好的 热稳定性归因于 TPE-S 在可见光区域具有很高的透明 度.<smiles>CSc1ccc(N(c2ccc(C)cc2)c2ccc(C(=C(c3ccc(N(c4ccc(C)cc4)c4ccc(C)cc4)cc3)c3ccc(N(c4ccc(C)cc4)c4ccc(C)cc4)cc3)c3ccc(N(c4ccc(C)cc4)c4ccc(C)cc4)cc3)cc2)cc1</smiles>

周祎和袁宁一等 ${ }^{[44]}$ 在 2019 年报道了以 9,9-二己基$9 H$-芴为核, 二甲硫基苯胺为端基基团的线性分子 FMT (29). 同理，用甲硫基取代传统的甲氧基有利于降低相 应分子的 HOMO 能级, 并提高器件的开路电压. FMT 通 过 Buchwald-Hartwig 反应，由二溴 9,9-二己基- $9 H$-芴与 二甲硫基苯胺偶联而合成的, 产率为 $64.6 \%$, 实验室合 成成本约为 $41.8 \$ \cdot \mathrm{g}^{-1}$, 远低于比 PTAA 和 spiroOMeTAD 的价格. FMT 膜对可见光几乎透明, 且具有良 好的热稳定性和适合 HOMO 能级 $(-4.89 \mathrm{eV})$. 基于非 掺杂 $\mathrm{FMT}$ 的 $\mathrm{ITO} / \mathrm{HTM} / \mathrm{MAPbI}_{3} / \mathrm{PCBM} / \mathrm{Al}$ 结构器件的效 率达到 19.06\%, 在相同条件下基于 PEDOT:PSS 的器件 
表 3 不同空穴传输材料的能级及制备成电池的性能参数

Table 3 Energy levels of different HTMs and the performance parameters of the devices

\begin{tabular}{|c|c|c|c|c|c|c|c|}
\hline HTM & $\mathrm{HOMO} / \mathrm{eV}$ & $\begin{array}{l}\text { Hole mobility/ } \\
\left(\mathrm{cm}^{2} \cdot \mathrm{V}^{-1} \cdot \mathrm{s}^{-1}\right)\end{array}$ & $V_{\mathrm{oc}} / \mathrm{V}$ & $\begin{array}{c}J_{\mathrm{sc}} / \\
\left(\mathrm{mA} \cdot \mathrm{cm}^{-2}\right)\end{array}$ & $\mathrm{FF}$ & $\mathrm{PCE} / \%$ & o Ref. \\
\hline ITO/TPE-S (28)/FA ${ }_{0.9} \mathrm{Cs}_{0.1} \mathrm{PbI}_{3} / \mathrm{PCBM} / \mathrm{ZnO} / \mathrm{Ag}$ & -5.29 & $1.2 \times 10^{-5}$ & 1.13 & 23.3 & 0.80 & $21.0^{\mathrm{b}}$ & 43 \\
\hline ITO/FMT (29)/MAPbI $3 / \mathrm{PCBM} / \mathrm{Al}$ & -4.89 & $2.28 \times 10^{-6}$ & 1.07 & 22.52 & 0.79 & $19.06^{\mathrm{b}}$ & 44 \\
\hline $\mathrm{FTO} / \mathrm{c}-\mathrm{TiO}_{2} / \mathrm{mp}-\mathrm{TiO}_{2} / \mathrm{MAPbI}_{3} / \mathrm{CJ}-03(\mathbf{3 0}) / \mathrm{Au}$ & -5.18 & $6.47 \times 10^{-5}$ & 1.11 & 22.89 & 0.79 & 20.06 & 45 \\
\hline $\mathrm{ITO} / \mathrm{SnO}_{2} /\left(\mathrm{FAPbI}_{3}\right)_{0.85}\left(\mathrm{MAPbBr}_{3}\right)_{0.15} / \mathrm{Py}-\mathrm{OMe}(\mathbf{3 1}) / \mathrm{Au}$ & -5.40 & $4.4 \times 10^{-3}$ & 1.11 & 22.82 & 0.76 & 19.28 & 46 \\
\hline $\mathrm{ITO} / \mathrm{SnO}_{2} / \mathrm{MAPbI}_{3} / \mathrm{TFAP}(\mathbf{3 2}) / \mathrm{Au}$ & -5.27 & $4.5 \times 10^{-3}$ & 1.11 & 22.63 & 0.74 & 19.74 & 47 \\
\hline $\mathrm{FTO} / \mathrm{c}-\mathrm{TiO}_{2} / \mathrm{mp}-\mathrm{TiO}_{2} / \mathrm{CsMAFA} / \mathrm{KR} 374(\mathbf{3 3}) / \mathrm{Au}$ & -5.06 & $1.2 \times 10^{-6}$ & 1.09 & 23.15 & 0.76 & 19.26 & 48 \\
\hline $\mathrm{FTO} / \mathrm{c}-\mathrm{TiO}_{2} / \mathrm{mp}-\mathrm{TiO}_{2} / \mathrm{CsMAFA} / \mathrm{DBC}-\mathrm{OMeDPA}(\mathbf{3 4}) / \mathrm{Au}$ & -5.26 & $8.8 \times 10^{-4}$ & 1.13 & 24.8 & 0.79 & 22.0 & 50 \\
\hline $\mathrm{FTO} / \mathrm{TiO}_{2} / \mathrm{MAPbI}_{3} / p \mathrm{Ph}-2 \mathrm{MODPACz}(\mathbf{3 5}) / \mathrm{Au}$ & -5.22 & $9.05 \times 10^{-5}$ & 1.09 & 23.22 & 0.78 & 19.74 & 51 \\
\hline $\mathrm{FTO} / \mathrm{c}-\mathrm{TiO}_{2} / \mathrm{CH}_{3} \mathrm{NH}_{3} \mathrm{PbI}_{3-x} \mathrm{Cl}_{x} / \mathrm{JY} 8(\mathbf{3 6}) / \mathrm{Ag}$ & -5.19 & $9.65 \times 10^{-4}$ & 1.08 & 21.9 & 0.81 & 19.14 & 52 \\
\hline $\mathrm{FTO} / \mathrm{c}-\mathrm{TiO}_{2} / \mathrm{SnO}_{2} /\left(\mathrm{FAPbI}_{3}\right)_{0.85}\left(\mathrm{MAPbBr}_{3}\right)_{0.15} / \mathrm{PDO} 2(\mathbf{3 7}) / \mathrm{Au}$ & -5.24 & $5.93 \times 10^{-4}$ & 1.15 & 23.9 & 0.74 & 20.2 & 53 \\
\hline $\mathrm{FTO} / \mathrm{TiO}_{2} / \mathrm{MAPbI} / \mathrm{DCZ}-\mathrm{OMeTAD}(\mathbf{3 8}) / \mathrm{MoO}_{3} / \mathrm{Ag}$ & -5.27 & $6.5 \times 10^{-4}$ & 1.06 & 25.14 & 0.81 & 21.66 & 54 \\
\hline $\mathrm{ITO} / \mathrm{C}_{60} / \mathrm{MAPbI}_{x} \mathrm{Cl}_{3-x} / \mathrm{FBA} 3(\mathbf{3 9}) / \mathrm{MoO}_{3} / \mathrm{Ag}$ & -5.07 & $2.12 \times 10^{-4}$ & 1.09 & 22.12 & 0.80 & $19.27^{\mathrm{b}}$ & 55 \\
\hline $\mathrm{FTO} / \mathrm{SnO}_{2} / \mathrm{FA}_{0.83} \mathrm{Cs}_{0.17} \mathrm{~Pb}\left(\mathrm{I}_{0.9} \mathrm{Br}_{0.1}\right)_{3} / \mathrm{V} 1091(\mathbf{4 0}) / \mathrm{Au}$ & -5.17 & $1.3 \times 10^{-5}$ & 1.11 & 22.5 & 0.81 & 20.2 & 56 \\
\hline $\mathrm{FTO} / \mathrm{SnO}_{2} / \mathrm{Cs}_{0.17} \mathrm{FA}_{0.83} \mathrm{~Pb}\left(\mathrm{I}_{0.9} \mathrm{Br}_{0.1}\right)_{3} / \mathrm{TAT}^{t}{ }^{\mathrm{B}} \mathrm{BuSty}(\mathbf{4 1}) / \mathrm{Au}$ & $\mathrm{NR}^{a}$ & $\mathrm{NR}^{a}$ & 1.15 & 22.1 & 0.80 & 20.3 & 47 \\
\hline
\end{tabular}

${ }^{a} \mathrm{NR}=$ not reported. ${ }^{b}$ Dopant-free.

效率仅为 13.9\%. TPE-S (28)、FMT (29)和上文讨论的 DBTMT (23) 是为数不多的几种使用甲硫基封端的低成 本、高性能有机小分子空穴材料, 甲硫基取代基在其它 空穴传输材料的分子设计中值得借鉴.

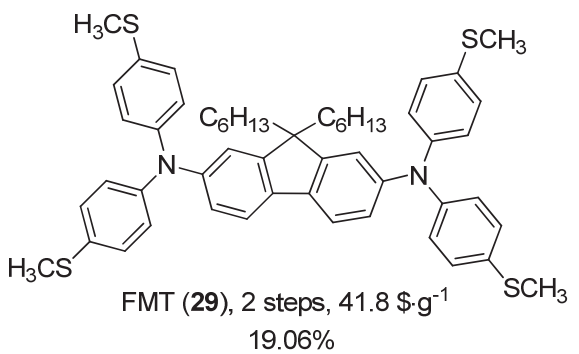

与四苯基乙烯相比, 四苯基丁二烯具有更好的平面 性和共轭程度, 有利于增强分子内电荷离域化. 邵光课 题组 ${ }^{[45}$ ]报道了由四苯基丁二烯中心骨架和二苯胺端基 基团组成的空穴传输材料 CJ-03 (30), 使用简单的合成 方法和简便的纯化技术即可获得, 实验室制备成本为 $34.43 \$ \cdot \mathrm{g}^{-1}$. CJ-03 具有扭曲的 “螺旋状” 结构, 有利于 构建三维电荷传输系统, 使其具有良好的空穴传输能 力，同时分子间的松散堆积使其易于溶解在有机溶剂 中, 形成高质量的薄膜. 当将 CJ-03 用作空穴传输材料 时, 最高能量转换效率达到 $20.06 \%\left(J_{\mathrm{sc}}=22.89 \mathrm{~mA}\right.$ ・ $\mathrm{cm}^{-2}, V_{\mathrm{oc}}=1.11 \mathrm{~V}, \mathrm{FF}=78.9 \%$ ), 优于基于 spiroOMeTAD 的电池性能 $(\mathrm{PCE}=18.90 \%)$.

2018 年, 崔涁涁和陈棋等 ${ }^{[46]}$ 报道了以萠为 $\pi$ 桥的 $\mathrm{D}-\pi-\mathrm{D}$ 结构三芳胺衍生物 Py-OMe (31), 由三芳胺硼酸 酯与四溴萠经 Suzuki-Miyaura 交叉偶联一步合成, 后处 理只需要简单的重结晶纯化, 产率为 $89 \%$, 实验室合成 成本为 $50.1 \$ \cdot \mathrm{g}^{-1}$. 将 Py-OMe 作为空穴传输材料应用于

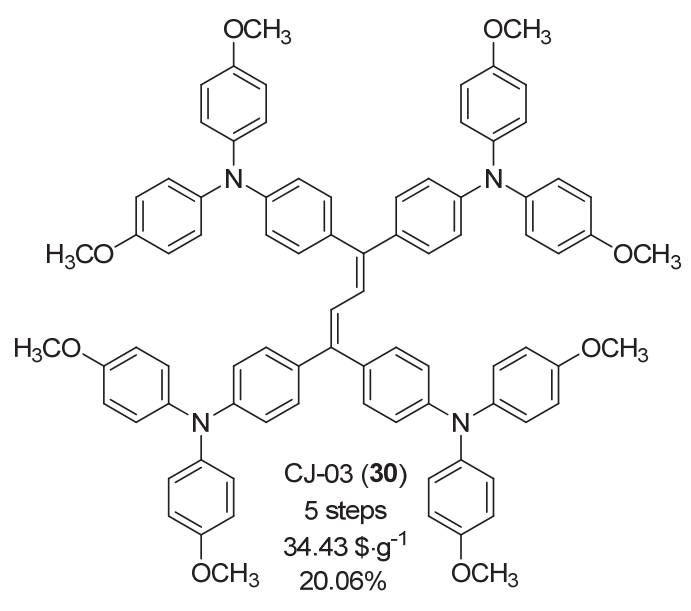

$\left(\mathrm{FAPbI}_{3}\right)_{0.85}\left(\mathrm{MAPbBr}_{3}\right)_{0.15}$ 钙钛矿太阳能电池中, 作者采 用较大的 FA 阳离子代替 MA 进一步降低其能带隙并将 光吸收范围扩展到红外区域, 并掺杂了澳化物以延长电 荷载流子的寿命. 在掺杂 Li-TFSI 和 TBP 后, 基于 Py$\mathrm{OMe}$ 的电池器件获得的最高效率为 $19.23 \%$, 高于同一 实验条件下基于 spiro-OMeTAD 的器件效率 $(\mathrm{PCE}=$ $18.57 \%$ ). 进一步地, 我们课题组和合作者 ${ }^{[47]}$ 将二甲基 芴基团取代四胺萠上的甲氧基苯基团, 通过一步 $\mathrm{C}-\mathrm{N}$ 偶联得到 1,3,6,8-四( $N$-对甲氧基苯- $N$-二甲基芴胺基)芘 (TFAP) (32). TFAP 的实验室制备成本为 $46 \$ \cdot \mathrm{g}^{-1}$, 只有 spiro-OMeTAD 成本的一半左右. 空穴传输材料 TFAP 中芴基单元的引入，增强了材料的热稳定性，降低了 HOMO 能级, 更有利于空穴的注入和传输. 以 TFAP 为 空穴传输材料, 制备了䥻钛矿太阳能电池, 取得最高能 量转化效率为 $19.74 \%\left(J_{\mathrm{sc}}=22.63 \mathrm{~mA} \cdot \mathrm{cm}^{-2}, V_{\mathrm{oc}}=1.11 \mathrm{~V}\right.$, $\mathrm{FF}=74.05 \%)$. 在相同实验条件和浓度下，使用 spiro-OMeTAD 的电池能量转化效率分别为 $19.9 \%$. 芴 基团的引入还能有效改善器件的迟滞现象和稳定性. 
Py-OMe (31)、TFAP (32) 和上文讨论的 OMe-TATPyr (19) 是目前报道的三种基于萠的高性能小分子空穴传输材 料, 表明萠是一类用于设计有机功能分子的优势骨架, 有望在今后的空穴传输材料分子设计与合成中得到进 一步应用.<smiles>COc1ccc(N(c2ccc(OC)cc2)c2ccc(-c3cc(-c4ccc(N(c5ccc(OC)cc5)c5ccc(OC)cc5)cc4)c4ccc5c(-c6ccc(N(c7ccc(OC)cc7)c7ccc(OC)cc7)cc6)cc(-c6ccc(N(c7ccc(OC)cc7)c7ccc(OC)cc7)cc6)c6ccc3c4c65)cc2)cc1</smiles>

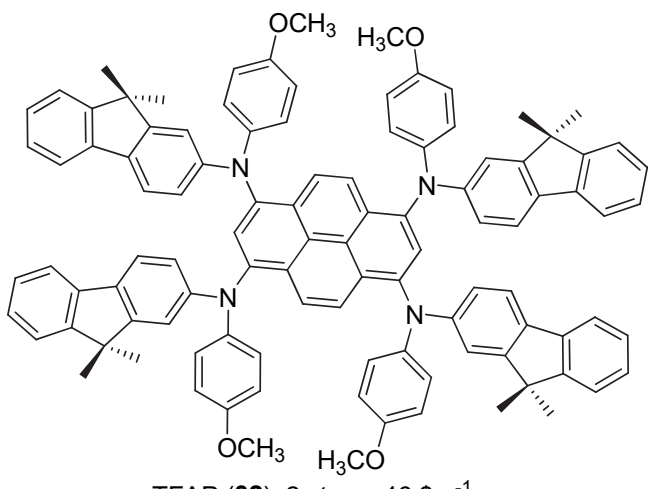

TFAP (32), 2 steps, $46 \$ \cdot g^{-1}$ $19.74 \%$

大部分上述分子都由一个 $\pi$-共轭骨架和四个三芳 胺端基基团组成, 在此类分子中, 新颖共轭骨架的使用 是分子设计的关键. 2017 年, Nazeeruddin 等 ${ }^{[48]}$ 合成了基 于双环烯烃骨架的三芳胺空穴传输材料 KR374 (33), 在 电池器件中取得 $19.2 \%$ 效率. 当 KR374 分子骨架中的硫 原子被替换成氧原子或砜基时, 所得材料在器件中的性 能明显降低, 表明 KR374 与钻铁矿之间的 Pb-S 相互作 用对器件性能有重要影响. 此外, 鉴于螺旋烯的良好溶 解度和独特的电子结构和互补分子堆积 ${ }^{[49]}$, 王鹏等 ${ }^{[50]}$ 合成了基于双螺旋烯二苯并丙烯(DBC)骨架的三芳胺空 穴传输材料 DBC-OMeDPA (34). 该分子的制备首先从 2,7-二澳-9-芴酮以 70\%产率得到四溴二苯并丙烯 (4Br-DBC), 然后经 Buchwald-Hartwig 胺化偶联得到, 总产率高达 $91 \%$, 实验室合成成本估计低于 $15 \$ \bullet \mathrm{g}^{-1}$. DBC-OMeDPA 的 HOMO 轨道离域在整个 $\pi$ 共轭骨架上,
有利于分子间的空穴跳跃. 同时它具有三维分子堆积和 多向空穴传输特性。与 spiro-OMeTAD 相比, DBCOMeDPA 具有更高的空穴迁移率 $\left(8.8 \times 10^{-4} \mathrm{~cm}^{2} \bullet \mathrm{V}^{-1}\right.$. $\mathrm{S}^{-1}$ ). 以 DBC-OMeDPA 作为空穴传输材料的钙铁矿器 件获得了最高 $22 \%$ 的效率. 更重要的是, 这种新型空穴 传输材料较高的玻璃化转变温度 $\left(154{ }^{\circ} \mathrm{C}\right)$ 允许器件在光 和热的双重压力下长期运行.

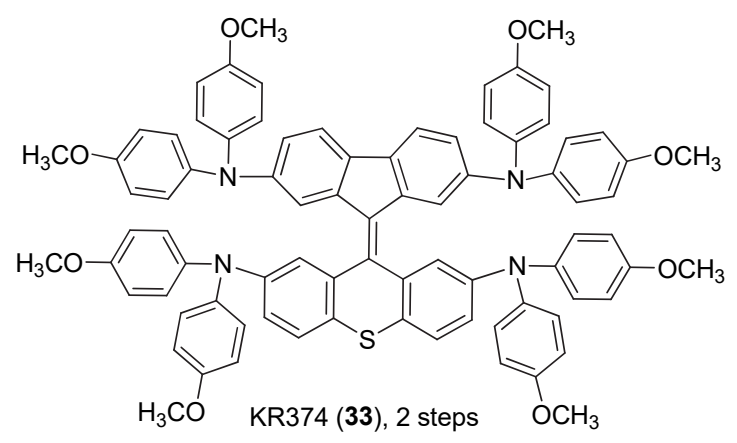
$19.26 \%$

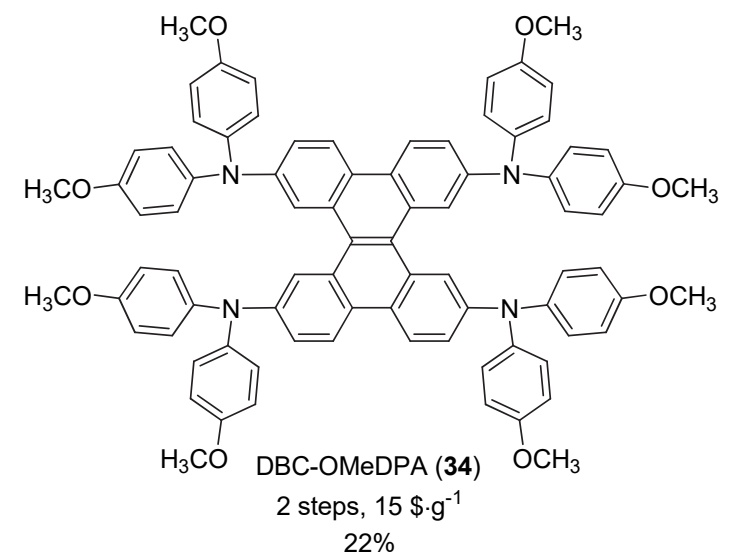

从前面关于 SFXDAnCBZ (9)和 YK1 (17)的讨论中 可知, 使用 $N^{3}, N^{6}$-双(二-4-茴香基氨基)-9H-咔唑(Dan$\mathrm{CBZ}$ )基团可以起到多个胺基的效果. 类似地, 李灿和郭 金等 ${ }^{[51]}$ 发现, 通过苯环直接连接两个 DAnCBZ 基团所 得到的 $p$ Ph-2MODPACz (35) 就是非常优秀的空穴传输 材料. 使用掺杂和未掺杂 $p \mathrm{Ph}-2 \mathrm{MODPACz}$ 的器件效率 分别约为 $20 \%$ 和 $16.07 \%$, 两者都比使用 spiro-OMeTAD 的器件效果要好. 此外, 朱琳娜课题组 ${ }^{[52]}$ 报道了噻二唑 并吡啶基团桥联的 DAnCBZ 衍生物 JY8 (36). JY8 具有 合适的 HOMO 能级以及较好的空穴迁移率 $\left(9.65 \times 10^{-4}\right.$ $\mathrm{cm}^{2} \cdot \mathrm{V}^{-1} \cdot \mathrm{s}^{-1}$ ). 使用 $\mathrm{JY} 8$ 作为空穴传输材料的钙铁矿器 件可实现 $19.14 \%$ 的能量转换效率, 其短路电流为 21.94 $\mathrm{mA} \cdot \mathrm{cm}^{-2}$, 开路电压为 $1.08 \mathrm{~V}$, 填充因子为 $81 \%$. 有趣的 是, 当将 JY8 的噻二唑并吡啶桥基换成苯并噻二唑时 (图 9), 所得到的 JY5 在电池中效率下降为 $17.13 \%$. 作 者认为 $\mathrm{JY} 8$ 中的噻二唑并吡啶单元的吸电子能力的增 强提高了分子间偶极-偶极相互作用, 有利于电荷传输. 同时, JY8 具有更好的平面性, 扩大了分子的 $\pi$ 共轭和电 
子离域. 结果表明, 功能分子结构微小变化就可能对器 件性能产生重要的影响.
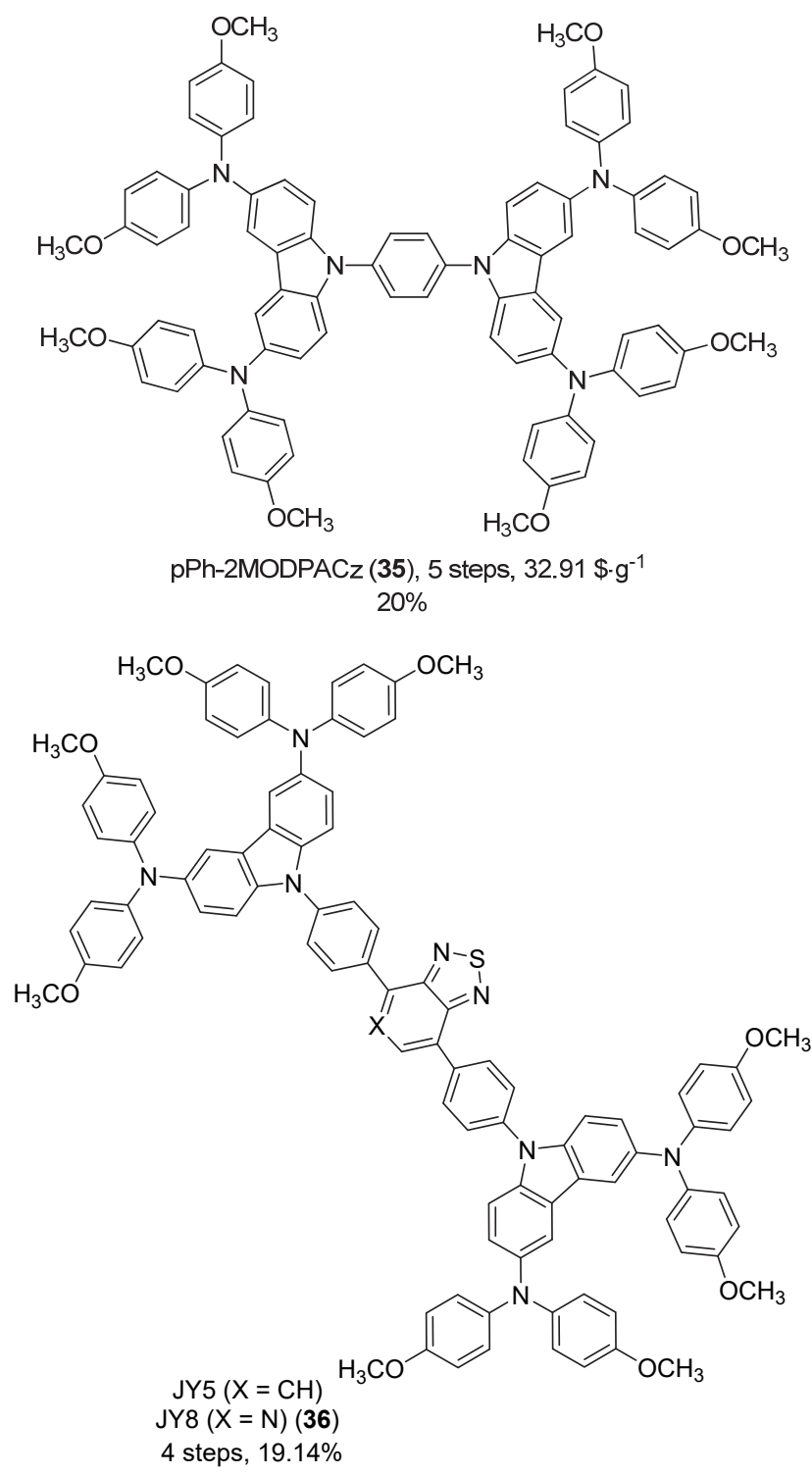

图 $9 \mathrm{JY} 5$ 和 JY8 的结构式

Figure 9 Structures of JY5 and JY8

除了使用四个胺基基团之外，利用三个胺基基团也 能合成高性能空穴传输材料. 李华明和陈敏等 ${ }^{[53]}$ 合成 了以吩噻嗪 5,5-二氧化物(PDO)为核心的含有三个胺基 基团的空穴传输材料 PDO2 (37). PDO 是一类杂环共轭 单元, 具有对称的非平面结构, 可以通过吩噻嗪一步氧 化获得. 通过在核心基团上引入砜基，可以有效地调节 电子密度分布以及 $\mathrm{HOMO}$ 能级. 使用 PDO2 作为空穴传 输材料的电池器件取得 $20.2 \%$ 的能量转化效率 $\left(J_{\mathrm{sc}}=23.9\right.$ $\mathrm{mA} \cdot \mathrm{cm}^{-2}, V_{\mathrm{oc}}=1.15 \mathrm{~V}, \mathrm{FF}=73.6 \%$ ), 并且在老化 $500 \mathrm{~h}$ 后仍具有良好的稳定性. 此外, 王照奎等 ${ }^{[54]}$ 报道了基于 吲哚并咔唑中心核的三胺化合物 DCZ-OMeTAD (38). 吲哚并咔唑具有两个稠合的咔唑环, 可以有效降低材料
的 HOMO 能级, 在相应器件中可以实现高开路电压和 良好性能. 以 DCZ-OMeTAD 为空穴传输材料，在 $\mathrm{CH}_{3} \mathrm{NH}_{3} \mathrm{PbI}_{3}$ 和 $\left(\mathrm{FAPbI}_{3}\right)_{1-x}\left(\mathrm{MAPbI}_{3}\right)_{x}$ 钙钛矿太阳能电池 分别取得 $19.81 \%$ 和 $21.66 \%$ 的能量转换效率.<smiles>COc1ccc(N(c2ccc(OC)cc2)c2ccc(N3c4ccc(N(c5ccc(OC)cc5)c5ccc(OC)cc5)cc4S(=O)(=O)c4cc(N(c5ccc(OC)cc5)c5ccc(OC)cc5)ccc43)cc2)cc1</smiles>

PDO2 (37), 4 steps, $61.27 \$ \cdot \mathrm{g}^{-1}$ $20.2 \%$<smiles>COc1ccc(N(C2=CC=c3c4ccc(N(c5ccc(OC)cc5)c5ccc(OC)cc5)cc4c(n3-c3ccc(N(c4ccc(OC)cc4)c4ccc(OC)cc4)cc3)=C2)c2ccc(OC)cc2)cc1</smiles>

除了四胺或三胺化合物, 桥联二胺化合物也是发展 高性能有机小分子空穴传输材料的重要结构. 苂蒽基团 具有低廉的价格、高度平面结构以及良好的热/电化学稳 定性等. 李忠安及其同事 ${ }^{[55]}$ 开发了一类基于苂葱骨架 的二胺化合物 FBA3 (39), 在钙钛矿太阳能电池中用作<smiles>COc1ccc(N(c2ccc(/C=C/c3ccc4c5ccc6cccc-6c(N(c6ccc(OC)cc6)c6ccc(OC)cc6)ccc(cc5)ccc5ccc-4c4c3cccc54)cc2)c2ccc(OC)cc2)cc1</smiles> 
非掺杂空穴传输材料, 实现了 $19.27 \%$ 的能量转换效率. FBA3 的实验室合成成本为 $14.75 \$ \cdot \mathrm{g}^{-1}$.

以上讨论的小分子材料均为经典的三芳胺类化合 物, 通过改变中心核的结构达到优化器件性能的目的. 最近, Wang 和 Snaith 等 ${ }^{[56]}$ 通过一步法从非常普通且便宜 的苯胺前体经无过渡金属催化合成基于烯胺的一类全 新结构的空穴传输材料 V1091 (40). 该化合物过在 $(+/$ 一)樟脑磺酸(CSA)存在下由苯胺前体与 2,2-双(4-甲氧 基苯基) 乙醛反应制备, 将材料成本降低至 spiroOMeTAD 的 1/5(图 10). 无过渡金属催化剂合成方法大 大简化了分子的合成, 并且产品的纯化过程只需要简单 的重结晶操作即可. 使用 V1091 作为空穴传输材料的器 件的最高能量转换效率为 $20.2 \%$. 未密封器件在相对湿 度为 $45 \%$ 的环境空气中存储 $800 \mathrm{~h}$ 后, 仍保持其原始效 率的 96\%, 而基于 spiro-OMeTAD 制备的器件相同条件 下效率下降至初始的 $42 \%$. 另外, 烯胺类分子可以通过 溶液和真空工艺进行处理, 为大面积钙钛矿电池以及其 他光电器件应用提供新的可能性.
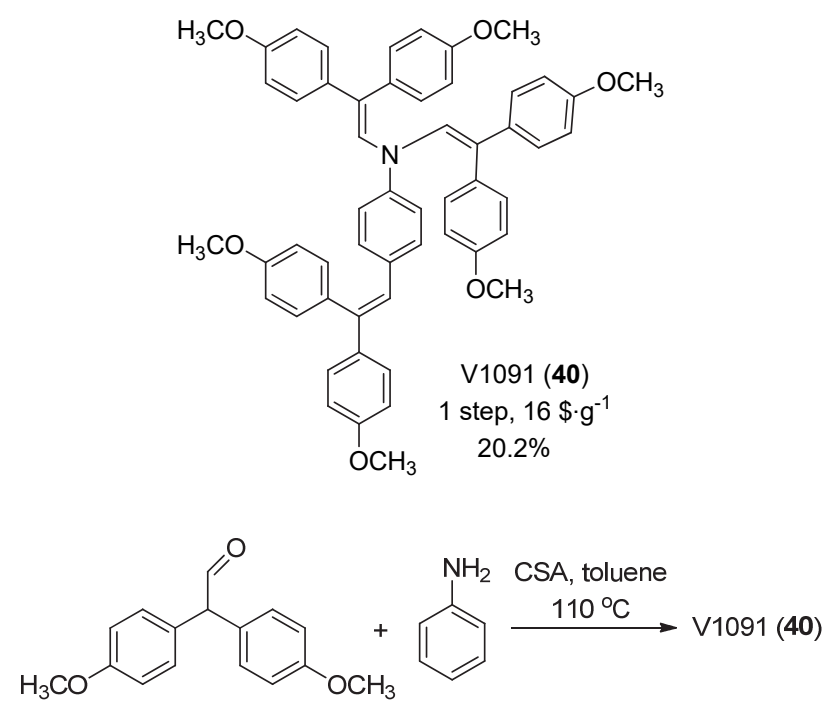

图 $10 \mathrm{~V} 1091$ (40)的合成路线

Figure 10 Synthetic route of V1091 (40)

此外, Wang 等 ${ }^{[57]}$ 合成了一种基于三氮杂三聚狮的 高效、低成本的空穴传输材料 TAT- ${ }^{t} B u S t y ~(41)$, 并使用 低成本的叔丁氧基苯乙烯取代常用的二甲氧基二苯胺 基团. TAT- ${ }^{t}$ BuSty 的合成成本为 $69.9 \$ \cdot \mathrm{g}^{-1}$. 使用 TAT${ }^{t} \mathrm{BuSty}$ 作为 $\mathrm{Cs}_{0.17} \mathrm{FA}_{0.83} \mathrm{~Pb}\left(\mathrm{I}_{0.9} \mathrm{Br}_{0.1}\right)_{3}$ 钙铁矿太阳能电池中 的空穴传输材料取得了 $20.3 \%$ 的最高能量转换效率(稳 定的效率为 $19.4 \%$ ), 与基于 spiro-OMeTAD 的参比器件 效率相当.

\section{4 结论与展望}

虽然钙铁矿太阳电池在近十年得到飞速的发展, 最

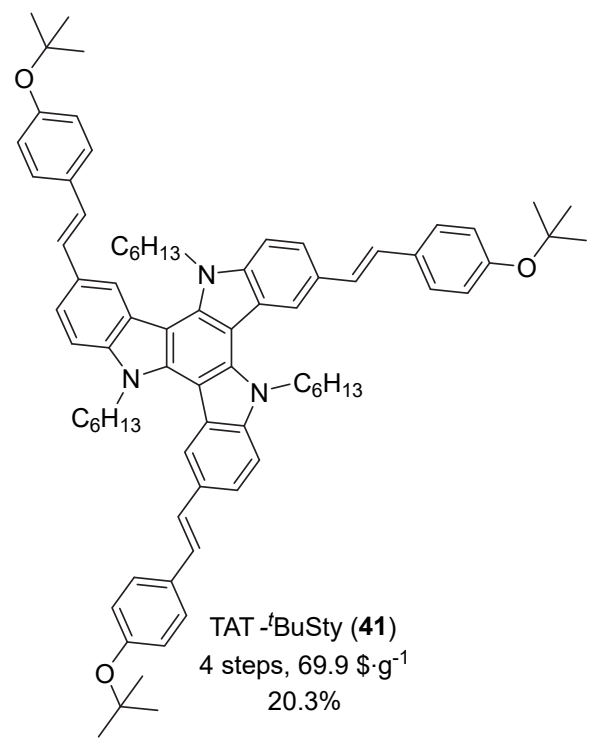

高能量转换效率超过 $25 \%$, 但钙钠矿太阳能电池在走向 产业化的过程中仍存较大的障碍, 比如电池的稳定性等 较差. 人们已经在寻求廉价、高效、稳定的新型空穴传 输材料方面取得了许多重要进展. 本文讨论了近期发展 的能量转换效率大于 $19 \%$ 的高性能有机小分子空穴传 输材料, 并分析了它们的结构特征与合成方法. 这些工 作表明, 使用螺环结构、噻吩衍生物或其它一些平面性 骨架基团可以发展出低成本、高性能的有机小分子空穴 传输材料, 有望取代 spiro-OMeTAD 在钙钛矿电池中获 得实际应用. 其中, 螺环结构的引入提高了材料的玻璃 转化温度, 改善了材料使用过程中的结晶性质. 而且, 非平面的三维螺环结构使得材料具有良好的溶解性, 有 利于形成高质量均匀的空穴传输材料薄膜. 可能的一个 缺点是螺型结构的存在会增加合成的难度, 限制了其在 钙钛矿领域的进一步商业化应用. 噻吩衍生物因其高的 电荷迁移率在有机光伏中表现出优异的性能. 噻吩结构 的引入可以提高材料的迁移率, 提高电池的短路电流; 同时，噻吩上的 $\mathrm{S}$ 原子为富电子基团，可以作为路易斯 碱与钙钛矿上未配位的 $\mathrm{Pb}$ 相互作用, 实现缺陷的针化. 在其它分子结构的 HTM 设计中, 研究者还通过引入平 面性强的分子骨架, 来提高材料的空穴迁移率. 为了降 低材料成本, 以廉价的原料通过有限的步骤进行简单合 成，并通过容易的纯化过程得到.

从器件性能优化的研究中可知, 小分子空穴传输材 料的母核结构、分子构型、封端基团、连接单元、烷基 链长度以及杂原子的使用等对材料和电池的性能都有 重要的影响, 是功能分子设计需要着重考虑的因素. 比 如, 甲氧基的引入既能提高材料的溶解性, 又能调节 $\mathrm{HOMO}$ 能级. 基于 $\mathrm{Pb}-\mathrm{S}$ 相互作用, 研究者在材料的端 基引入含 $\mathrm{S}$ 原子的甲硫基, 利用它们与钻钛矿之间的相 
互作用实现有效的缺陷钝化, 进一步提高器件的效率和 稳定性. 平面性强的芴基团也常用来调节材料的空穴迁 移率以及 HOMO 能级. 同时, 芴基基团也有望作为一种 优势封端基团在空穴传输材料的分子设计中得到重视. 就烷基链的长度而言, 虽然烷基链有利于提高材料的溶 解度, 但太长的烷基链可能会引起分子间电荷传输的障 碍. 所以应使用适当长度的烷基链来综合调节分子的溶 解度和电荷传输性能.

通常来说, 合适的 HOMO 能级有利于减少能量损 失和增加 $V_{\mathrm{oc}}$. 在同一实验条件下, 新材料的 HOMO 能 级越深, 对应器件的 $V_{\mathrm{oc}}$ 值就越高. 从电荷传输平衡的 角度来看, 较好的空穴迁移率有利于实现更高的器件效 率. 但需要指出的是, 能量转换效率和器件的结构、每 一层所使用的材料、各层材料的能级匹配、器件制备工 艺以及测试条件等多种因素息息相关, 不能单纯从 HOMO 能级和空穴迁移率的横向比较判断空穴传输材 料的好坏. 例如, 文中讨论的 TFAP (32) 具有最高空穴 迁移率 $\left(4.5 \times 10^{-3} \mathrm{~cm}^{2} \cdot \mathrm{V}^{-1} \cdot \mathrm{s}^{-1}\right)$, 但是其器件效率仅为 $19.4 \%{ }^{[47]}$, 这可能是由于电子传输材料的较低电子迁移 率引起 $\left(10^{-5} \sim 10^{-3} \mathrm{~cm}^{2} \cdot \mathrm{V}^{-1} \cdot \mathrm{s}^{-1}\right)$. 又比如, 表 1 中所列 的 G2 (10)分子 ${ }^{[21]}$ 和 spiro-OMeTAD 相比, 两者具有相同 的 HOMO 能级, 但 G2 具有更高的空穴迁移率, 而使用 spiro-OMeTAD 的器件却表现出更高的效率 ${ }^{[11]}$. 一方面, 两者材料的器件结构不同. 另一方面, 基于 spiro-OMeTAD 的效率是经过多次优化得到的结果. 此 外, Py-OMe (31 $)^{[46]}$ 和 KR374 (33) ${ }^{[48]}$ 两者空穴迁移率相 差 3 个数量级, HOMO 能级相差了 $0.34 \mathrm{eV}$, 但其光电转 换效率却非常接近(分别为 $19.26 \%$ 和 19.28\%). 一个原 因是两种器件使用的是不同的钙钛矿材料, 两种空穴传 输材料和相对应的钙钛矿都有比较匹配的能级, 所以都 有较好的空穴提取效果. 总之, 表 $1 \sim 3$ 所列出的能量转 换效率都是在相对应的器件结构中所取得的结果, 不同 材料之间的横向比较一定要慎重.

通过文中三种类型 HTM 的讨论和总结, 可以归纳 出高效稳定空穴传输材料所需具备的一些共同特征, 作 为进一步分子设计的指导. (1)通过使用螺环等扭曲结 构、改变取代基及引入适当的烷基链等方法, 使有机空 穴传输材料具有良好的溶解性, 能够进行溶液加工; 同 时又有较好的成膜特性, 有利于空穴传输, 并且起到保 护钙钛矿层的作用. (2)分子要具有合适的 HOMO 能级, 并且 HOMO 能级尽可能接近钙钛矿层的价带, 以有效 地提取光生空穴并阻挡光生电子. 在分子结构中加入吸 电子基团, 可以达到有效降低 HOMO 能级的效果, 从而 有利于增加 PSCs 的开路电压. (3)通过增强分子平面性、 扩大共轭程度、引入给受体以及调节分子堆积等方法增
强薄膜高迁移率. 空穴传输材料要具有适度的空穴迁移 率 $\left(\approx 10^{-4} \mathrm{~cm}^{2} \cdot \mathrm{V}^{-1} \cdot \mathrm{s}^{-1}\right)$, 能保证空穴在空穴传输层与钲 钛矿层界面分离后进行有效的传输. (4)空穴传输材料要 具有足够好的热稳定性、光稳定性和对湿度的稳定性, 这些稳定性在一定程度上影响器件的稳定性. 在分子结 构中引入疏水性的官能团, 可以防止水进入到钙钛矿 层. (5)在空穴传输材料结构中适当引入不同极性的基 才，有利于利用空穴传输材料与钙钛矿材料的相互作 用，进一步提高器件的效率和稳定性.

低成本、高性能的有机小分子空穴传输材料的开发 仍将是近期的研究热点与前沿. 发展非掺杂的空穴传输 材料是其中一个关注的重点. 这主要是由于双(三氟甲 烷)磺酰亚胺锂盐等添加剂的吸湿性质会导致钻钛矿加 速降解, 限制了器件的长期稳定性, 而且还会增加器件 制备的复杂性和成本. 使用平面型较好的 $\pi$-共轭芳香基 才可以增强分子间的堆积和空穴迁移率，为发展非掺杂 的空穴传输材料提供一种可能. 通过使用电子给体一受 体(D-A)结构，来增加分子内电荷的离域作用和分子间 的相互作用, 也是发展非掺杂空穴传输材料和提供器件 稳定性的一种重要方法.

\section{References}

[1] (a) Jena, A. K.; Kulkarni, A.; Miyasaka, T. Chem. Rev. 2019, 119, 3036.

(b) Grätzel, M. Acc. Chem. Res. 2017, 50, 487.

(c) Yu, D.; Hu, Y.; Shi, J.; Tang, H.; Zhang, W.; Meng, Q.; Han, H.; Ning, Z.; Tian, H. Sci. China: Chem. 2019, 62, 684.

[2] Saliba, M.; Correa-Baena, J.-P.; Grätzel, M.; Hagfeldt, A.; Abate, A Angew. Chem., Int. Ed. 2018, 57, 2554.

[3] Kojima, A.; Teshima, K.; Shirai, Y.; Miyasaka, T. J. Am. Chem. Soc. 2009, 131, 6050

[4] Kim, H.-S.; Lee, C.-R.; Im, J.-H.; Lee, K.-B.; Moehl, T.; Marchioro, A.; Moon, S.-J.; Humphry-Baker, R.; Yum, J.-H.; Moser, J. E.; Grätzel, M.; Park, N.-G. Sci. Rep. 2012, 2, 1.

[5] Kim, G.; Min, H.; Lee, K. S.; Lee, D. Y.; Yoon, M.; Seok, S. I. Science 2020, 370, 108 .

[6] (a) Yang, S.; Fu, W.; Zhang, Z.; Chen, H.; Li, C.-Z. J. Mater. Chem. A 2017, 5, 11462 .

(b) Pham, H. D.; Yang, T. C.; Jain, S. M.; Wilson, G. J.; Sonar, P. Adv. Energy Mater. 2020, 10, 1903326.

(c) Wang, Y.; Han, L. Sci. China: Chem. 2019, 62, 822.

[7] (a) Pham, H. D.; Li, X.; Li, W.; Manzhos, S.; Kyaw, A. K. K.; Sonar, P. Energy Environ. Sci. 2019, 12, 1177.

(b) Rajagopal, A.; Yao, K.; Jen, A. K.-Y. Adv. Mater. 2018 , 1800455.

[8] (a) Urieta-Mora, J.; Garcia-Benito, I.; Molina-Ontoria, A.; Martin, N. Chem. Soc. Rev. 2018, 47, 8541.

(b) Gangala, S.; Misra, R. J. Mater. Chem. A 2018, 6, 18750.

(c) Kim, G.-W.; Choi, H.; Kim, M.; Lee, J.; Son, S. Y.; Park, T. Adv. Energy Mater. 2020, 1903403.

[9] (a) Wang, T.; Ding, D.; Zheng, H.; Wang, X.; Wang, J.; Liu, H.; Shen, W. Sol. RRL 2019, 3, 1900045 .

(b) Arora, N.; Dar, M. I.; Hinderhofer, A.; Pellet, N.; Schreiber, F.; Zakeeruddin, S. M.; Grätzel, M. Science 2017, 358, 768.

(c) Cao, J.; Wu, B.; Peng, J.; Feng, X.; Li, C.; Tang, Y. Sci. China: Chem. 2019, 62, 363.

[10] (a) Yang, W. S.; Noh, J. H.; Jeon, N. J.; Kim, Y. C.; Ryu, S.; Seo, J.; 
Seok, S. I. Science 2015, 348, 1234.

(b) Jung, E. H.; Jeon, N. J.; Park, E. Y.; Moon, C. S.; Shin, T. J.; Yang, T. Y.; Noh, J. H.; Seo, J. Nature 2019, 567, 511.

[11] Min, H.; Kim, M.; Lee, S.-U.; Kim, H.; Kim, G.; Choi, K.; Lee, J. H.; Seok, S. I. Science 2019, 366, 749.

[12] Rakstys, K.; Saliba, M.; Gao, P.; Gratia, P.; Kamarauskas, E.; Paek, S.; Jankauskas, V.; Nazeeruddin, M. K. Angew. Chem., Int. Ed. 2016, 55, 7464 .

[13] Jeon, N. J.; Na, H.; Jung, E. H.; Yang, T.-Y.; Lee, Y. G.; Kim, G.; Shin, H.-W.; Seok, S. I.; Lee, J.; Seo, J. Nat. Energy 2018, 3, 682

[14] Saliba, M.; Orlandi, S.; Matsui, T.; Aghazada, S.; Cavazzini, M.; Correa-Baena, J.-P.; Gao, P.; Scopelliti, R.; Mosconi, E.; Dahmen, K.-H.; Angelis, F. D.; Abate, A.; Hagfeldt, A.; Pozzi, G.; Grätzel, M.; Nazeeruddin, M. K. Nat. Energy 2016, 1, 15017.

[15] Cao, Y.; Li, Y.; Morrissey, T.; Lam, B.; Patrick, B. O.; Dvorak, D. J.; Xia, Z.; Kelly, T. L.; Berlinguette, C. P. Energy Environ. Sci. 2019, 12, 3502 .

[16] Xu, B.; Bi, D.; Hua, Y.; Liu, P.; Cheng, M.; Grätzel, M.; Kloo, L.; Hagfeldt, A.; Sun, L. Energy Environ. Sci. 2016, 9, 873.

[17] Bi, D.; Xu, B.; Gao, P.; Sun, L.; Grätzel, M.; Hagfeldt, A. Nano Energy 2016, 23, 138 .

[18] Xu, B.; Zhang, J.; Hua, Y.; Liu, P.; Wang, L.; Ruan, C.; Li, Y.; Boschloo, G.; Johansson, E. M. J.; Kloo, L.; Hagfeldt, A.; Jen, A. K.-Y.; Sun, L. Chem 2017, 2, 676.

[19] Zhang, J.; Xu, B.; Yang, L.; Ruan, C.; Wang, L.; Liu, P.; Zhang, W.; Vlachopoulos, N.; Kloo, L.; Boschloo, G.; Sun, L.; Hagfeldt, A.; Johansson, E. M. J. Adv. Energy Mater. 2018, 8, 1701209.

[20] Lee, D. Y.; Sivakumar, G.; Misra, M. R.; Seok, S. I. ACS Appl. Mater. Inter. 2020, 12, 28246.

[21] Gao, K.; Xu, B.; Hong, C.; Shi, X.; Liu, H.; Li, X.; Xie, L.; Jen, A. K-Y. Adv. Energy Mater. 2018, 8, 1800809.

[22] Akin, S.; Bauer, M.; Uchida, R.; Arora, N.; Jacopin,G.; Liu, Y.; Hertel, D.; Meerholz, K.; Mena-Osteritz, E.; Bäuerle, P.; Zakeeruddin, S. M.; Dar, M. I.; Grätzel, M. ACS Appl. Energy Mater. 2020, 3, 7456 .

[23] Park, S. J.; Jeon, S.; Lee, I. K.; Zhang, J.; Jeong, H.; Park, J.-Y.; Bang, J.; Ahn, T. K.; Shin, H.-W.; Kim, B.-G.; Park, H. J. J. Mater. Chem. A 2017, 5, 13220 .

[24] Zhu, X.-D.; Ma, X.-J.; Wang, Y.-K.; Li, Y.; Gao, C.-H.; Wang, Z.-K.; Jiang, Z.-Q.; Liao, L.-S. Adv. Funct. Mater. 2018, 1807094.

[25] (a) Son, D.; Lee, J.; Choi, Y.; Jang, I.; Lee, S.; Yoo, P.; Shin, H.; Ahn, N.; Choi, M.; Kim, D.; Park, N. Nat. Energy 2016, 1, 16081. (b) Li, X.; Zhang, W.; Wang, Y.-C.; Zhang, W.; Wang, H.-Q.; Fang, J. Nat. Commun. 2018, 9, 3806.

(c) Noel, N. K.; Abate, A.; Stranks, S. D.; Parrott, E. S.; Burlakov, V. M.; Goriely, A.; Snaith, H. J. ACS Nano 2014, 8, 9815.

[26] Xu, J.; Liang, L.; Mai, C.-L.; Zhang, Z.; Zhou, Q.; Xiong, Q.; Zhang, Z.; Deng, L.; Gao, P. Nanoscale 2020, 12, 13157.

[27] Gao, K.; Zhu, Z.; Xu, B.; Jo, S. B.; Kan, Y.; Peng, X.; Jen, A. K.-Y. Adv. Mater. 2017, 29, 1703980.

[28] Fang, L.; Zheng, A.; Ren, M.; Xie, X.; Wang, P. ACS Appl. Mater. Interfaces 2019, 11, 39001.

[29] Zhang, F.; Wang, Z.; Zhu, H.; Pellet, N.; Luo, J.; Yi, C.; Liu, X.; Liu, H.; Wang, S.; Li, X.; Xiao, Y.; Zakeeruddin, S. M.; Bi, D.; Gratzel, M. Nano Energy 2017, 41, 469.

[30] Petrus, M. L.; Schutt, K.; Sirtl, M. T.; Hutter, E. M.; Closs, A. C.; Ball, J. M.; Bijleveld, J. C.; Petrozza, A.; Bein, T.; Dingemans, T. J.; Savenije, T. J.; Snaith, H.; Docampo, P. Adv. Energy Mater. 2018, $8,1801605$.

[31] Hua, Y.; Chen, S.; Zhang, D.; Xu, P.; Sun, A.; Ou, Y.; Wu, T.; Sun, H.; Cui, B.; Zhu, X. J. Mater. Chem. A 2019, 7, 10200.

[32] Shen, C.; Wu, Y.; Zhang, H.; Li, E.; Zhang, W.; Xu, X.; Wu, W.;
Tian, H.; Zhu, W.-H. Angew. Chem., Int. Ed. 2019, 58, 3784.

[33] Jeon, N. J.; Lee, J.; Noh, J. H.; Nazeeruddin, M. K.; Gratzel, M.; Seok, S. I. J. Am. Chem. Soc. 2013, 135, 19087.

[34] (a) Ge, Q.-Q.; Shao, J.-Y.; Ding, J.; Deng, L.-Y.; Zhou, W.-K.; Chen, Y.-X.; Ma, J.-Y.; Wan, L.-J.; Yao, J.; Hu, J.-S.; Zhong, Y.-W. Angew. Chem., Int. Ed. 2018, 57, 10959.

(b) Wei, Q.; Ning, Z. Sci. China: Chem. 2019, 62, 5.

[35] Yin, X.; Zhou, J.; Song, Z.; Dong, Z.; Bao, Q.; Shrestha, N.; Bista, S. S.; Ellingson, R. J.; Yan, Y.; Tang, W. Adv. Funct. Mater. 2019, 1904300.

[36] Dong, Z.; Yin, X.; Ali, A.; Zhou, J.; Bista, S. S.; Chen, C.; Yan, Y.; Tang, W. J. Mater. Chem. C 2019, 7, 9455.

[37] Wang, J.; Zhang, H.; Wu, B.; Wang, Z.; Sun, Z.; Xue, S.; Wu, Y.; Hagfeldt, A.; Liang, M. Angew. Chem., Int. Ed. 2019, 58, 15721.

[38] Zhang, J.; Sun, Q.; Chen, Q.; Wang, Y.; Zhou, Y.; Song, B.; Jia, X.; Zhu, Y.; Zhang, S.; Yuan, N.; Ding, J.; Li, Y. Sol. RRL 2020, 4 , 1900421.

[39] Tu, B.; Wang, Y.; Chen, W.; Liu, B.; Feng, X.; Zhu, Y.; Yang, K.; Zhang, Z.; Shi, Y.; Guo, X.; Li, H.-F.; Tang, Z.; Djurišić, A. B.; He, Z. ACS Appl. Mater. Interfaces 2019, 11, 48556.

[40] Chen, Y.; Xu, X.; Cai, N.; Qian, S.; Luo, R.; Huo, Y.; Tsang, S.-W. Adv. Energy Mater. 2019, 9, 1901268.

[41] Oh, S.; Khan, N.; Jin, S.-M.; Tran, H.; Yoon, N.; Song, C. E.; Lee, H. K.; Shin, W. S.; Lee, J.-C.; Moon, S.-J.; Lee, E.; Lee, S. K. Nano Energy 2020, 72, 104708.

[42] Rakstys, K.; Paek, S.; Gao, P.; Gratia, P.; Marszalek, T.; Grancini, G.; Cho, K. T.; Genevicius, K.; Jankauskas, V.; Pisula, W.; Nazeeruddin, M. K. J. Mater. Chem. A 2017, 5, 7811.

[43] Jiang, K.; Wang, J.; Wu, F.; Xue, Q.; Yao, Q.; Zhang, J.; Chen, Y.; Zhang, G.; Zhu, Z.; Yan, H.; Zhu, L.; Yip, H.-L. Adv. Mater. 2020 1908011.

[44] Zhang, J.; Sun, Q.; Chen, Q.; Wang, Y.; Zhou, Y.; Song, B.; Yuan, N.; Ding, J.; Li, Y. Adv. Funct. Mater. 2019, 29, 1900484.

[45] Chen, J.; Xia, J.; Gao, W.-J.; Yu, H.-J.; Zhong, J.-X.; Jia, C.; Qin, Y.-S.; She, Z.; Kuang, D.-B.; Shao, G. ACS Appl. Mater. Interfaces 2020, 12, 21088.

[46] Cui, B.-B.; Zhu, C.; Yang, S.; Han, Y.; Yang, N.; Zhang, L.; Wang, Y.; Jia, Y.; Zhao, L.; Chen, Q. ACS Omega 2018, 3, 10791.

[47] Shao, J.-Y.; Yang, N.; Guo, W.; Cui, B.-B.; Chen, Q.; Zhong, Y.-W. Chem. Commun. 2019, 55, 13406.

[48] Rakstys, K.; Paek, S.; Grancini, G.; Gao, P.; Jankauskas, V.; Asiri, A. M.; Nazeeruddin, M. K. ChemSusChem 2017, 10, 3825.

[49] Shen, Y.; Chen, C.-F. Chem. Rev. 2012, 112, 1463.

[50] Ren, M.; Wang, J.; Xie, X.; Zhang, J.; Wang, P. ACS Energy Lett. 2019, 4, 2683

[51] Yu, W.; Yang, Q.; Zhang, J.; Tu, D.; Wang, X.; Liu, X.; Li, G.; Guo, X.; Li, C. ACS Appl. Mater. Interfaces 2019, 11, 30065.

[52] Ji, Y.; He, B.; Lu, H.; Xu, J.; Wang, R.; Jin, Y.; Zhong, C.; Shan, Y.; Wu, F.; Zhu, L. ChemSusChem 2019, 12, 1374.

[53] Ding, X.; Chen, C.; Sun, L.; Li, H.; Chen, H.; Su, J.; Li, H.; Li, H.; $\mathrm{Xu}, \mathrm{L} . ;$ Cheng, M. J. Mater. Chem. A 2019, 7, 9510.

[54] Ma, X.-J.; Zhu, X.-D.; Wang, K.-L.; Igbari, F.; Yuan, Y.; Zhang, Y.; Gao, C.-H.; Jiang, Z.-Q.; Wang, Z.-K.; Liao, L.-S. Nano Energy 2019, 63, 103865 .

[55] Sun, X.; Wu, F.; Zhong, C.; Zhu, L.; Li, Z. Chem. Sci. 2019, 10, 6899.

[56] Vaitukaityte, D.; Wang, Z.; Malinauskas, T.; Magomedov, A.; Bubniene, G.; Jankauskas, V.; Getautis, V.; Snaith, H. J. Adv. Mater. 2018, 30, 1803735 .

[57] Connell, A.; Wang, Z.; Lin, Y.-H.; Greenwood, P. C.; Wiles, A. A.; Jones, E. W.; Furnell, L.; Anthony, R.; Kershaw, C. P.; Cooke, G.; Snaith, H. J.; Holliman, P. J. J. Mater. Chem. C 2019, 7, 5235. 